\title{
Climate contributes to the evolution of pesticide resistance
}

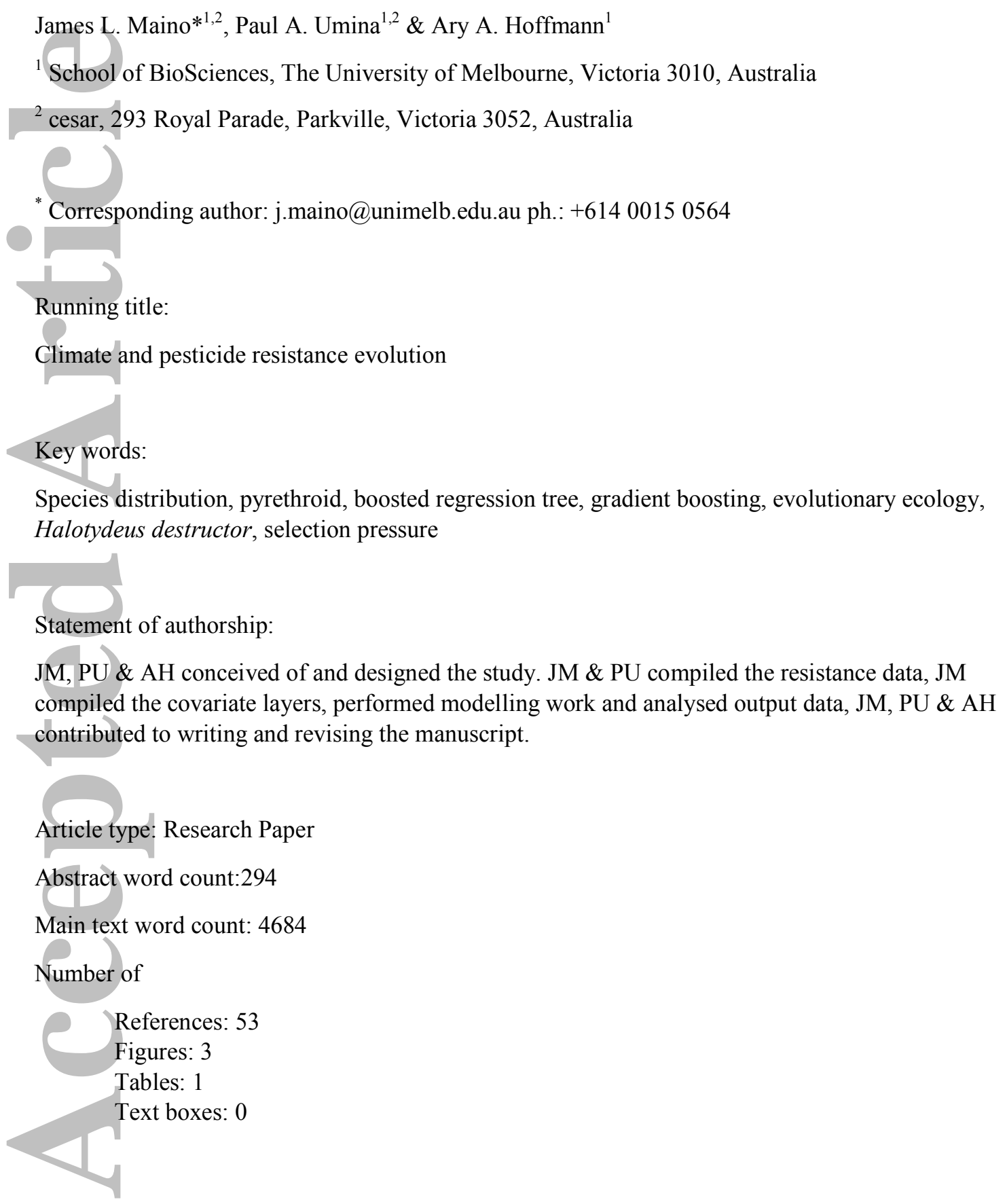

This is the author manuscript accepted for publication and has undergone full peer review but has not been through the copyediting, typesetting, pagination and proofreading process, which may lead to differences between this version and the Version record. Please cite this article as doi:10.1111/ geb.12692. 


\section{Abstract}

Aim

The evolution of pesticide resistance through space and time is of great economic significance to modern agricultural production systems, and consequently, is often well-documented. It can thus be used to dissect the evolutionary and ecological processes that underpin large-scale evolutionary responses. There are now nearly 600 documented cases of pesticide resistance in arthropod pests.

While the evolution of resistance is often attributed to the persistent use of chemicals for pest suppression, the rate of development of resistance should also depend on other factors including climatic conditions that influence population size and generation time. Here we test whether climatic variables are linked to resistance evolution by examining the spatial pattern of pyrethroid resistance in an important agricultural pest.

Location: Southern, agricultural regions of Australia

ror

Time period: $2007-2015$

Major taxa studied: The redlegged earth mite, Halotydeus destructor

$$
\text { ( }
$$

Methods

We quantified patterns of chemical usage based on paddock histories, and collated long-term climatic data. This data was then compared against presence-absence data on resistance using a boostedregression-tree approach, applied here for the first time to the spatial categorisation of pesticide resistance.

Results

While chemical usage was a key driver of resistance, our analysis revealed climatic-based signals in the spatial distribution of resistance, linked to regional variation in aridity, temperature seasonality, and precipitation patterns. Climatic regions supporting increased voltinism were positively correlated with resistance, in line with expectations that increased voltinism should accelerate evolutionary responses to selection pressures. 


\section{Main conclusions}

Our findings suggest the prediction of rapid evolutionary processes at continental scales, such as pesticide resistance, will be improved through methods that incorporate climate and ecology, in addition to more immediate selection pressures, such as chemical usage. Boosted regression trees present a powerful tool in the management of resistance issues that has hitherto not been utilised.
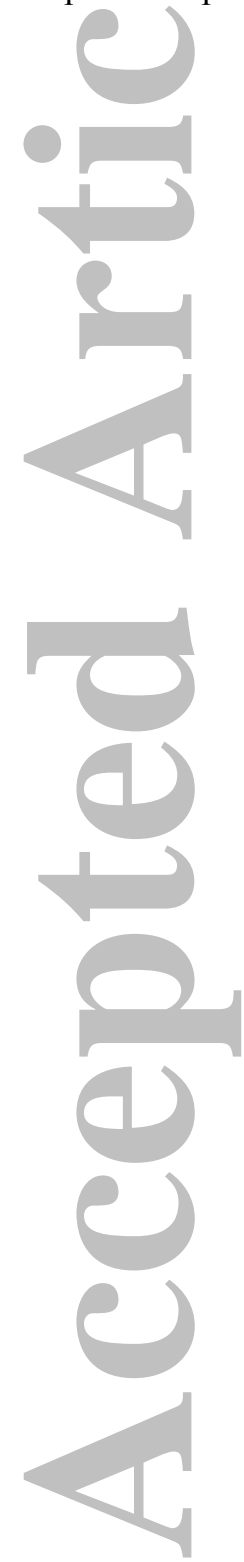


\section{Introduction}

Despite ongoing challenges with pesticide resistance in agricultural systems (Sparks \& Nauen, 2015), the evolutionary ecology of field resistance remains poorly understood. Lab-based experiments are able to demonstrate evolutionary responses to pesticide applications (Feng \& Isman, 1995), but it is

difficult to extend results to the field, where a complex network of biotic and abiotic factors interact to influence selection pressures for resistance (Kimball \& Levin, 1985). Models of resistance normally

focus on factors that determine the selection of alleles that confer pesticide resistance (resistance alleles) in populations and how these are affected by species biology and environmental factors (Georghiou \& Taylor, 1977; REX Consortium, 2013). However, it is often difficult to capture the level of complexity required for meaningful predictions to be made except in specific situations dealing with specific pests (Stratonovitch et al., 2014).

The evolution of resistance in agricultural pests is likely to depend not only on the number of chemical applications in crops, but also on climatic factors that influence resistance evolution in several ways. Resistance alleles are usually exceedingly rare (Roush \& Tabashnik, 1990) and therefore more likely to appear in large populations; climatic variables driving long-term abundance of pest species may help to explain patterns of field resistance. Climate can influence resistance evolution by affecting the generation time of multivoltine pests (Tobin et al., 2008), with shorter generation times expected to speed up the rate of resistance evolution. Climatic conditions can also influence selection pressures on resistance alleles by influencing the rate of breakdown of chemicals in the environment (Khodaverdi et al., 2016), increasing selection when cross resistance occurs between chemicals and climatic extremes (Patil et al., 1996), and increasing the susceptibility of organisms to chemicals when they are exposed to climatically stressful conditions (Polson et al., 2012)

To evaluate the overall impact of climatic factors on patterns of resistance development, well-studied cases of resistance are needed that vary spatially and/or temporally. Here we take advantage of the documented spatial spread of pyrethroid resistance in the redlegged earth mite (RLEM), Halotydeus destructor (Acari: Penthaleidae). This species was first detected in Australia in 1917 after it arrived 
from its native range in the Western Cape of South Africa. Since introduction, this polyphagous mite has emerged as one of the most important invertebrate pests affecting Australia's grain and pastoral industries (Sloane Cook \& King, 1989; Ridsdill-Smith, 1997; Murray et al., 2013). The suppression of RLEM below damaging threshold levels is heavily reliant on chemical control methods, such as applications of synthetic pyrethroids and organophosphates. Resistance to pyrethroid chemicals in RLEM was first reported at a single location in 2007 (Umina, 2007). It has since been detected in over 50 locations across Western Australia (Fig. 1) and genetic analyses indicate that resistance has evolved independently several times (Hoffmann et al., forthcoming).

RLEM spend over $90 \%$ of the time on or near to soil surface, generally only moving onto a plant to feed, which they do by lacerating the epidermis and consuming the exposed cell contents (RidsdillSmith, 1997). The lifecycle of RLEM, as well as changes in the distribution and abundance of this pest, are closely tied to climatic factors (Ridsdill-Smith \& Annells, 1997; Ridsdill-Smith et al., 2008).

The mite usually has 3-4 generations from autumn to early spring, depending on local climatic conditions, and then enters a summer diapausing period, with diapause broken and egg hatch triggered by a combination of rainfall and low temperature the following autumn (Wallace \& Mahon, 1971; McDonald et al., 2015). Long-distance wind-assisted dispersal of mites can occur when cadavers containing diapause eggs are blown (or otherwise transported, e.g. with silage) across the landscape. The lifecycle of RLEM restricts suitable areas to parts of southern Australia, South Africa and New Zealand. Within Australia, Hill et al. (2012) found the occurrence of RLEM was favoured in locations of high temperature seasonality, intermediately moist winter conditions with temperatures between $10-25^{\circ} \mathrm{C}$, and dry summer conditions.

RLEM prefer certain host-plants such as legumes and pastures over grasses, which has consequences for their abundance in crops (Ridsdill-Smith, 1997). Mite abundance is further modulated by crop condition (e.g. short pasture is less favourable than long pasture, presumably due to the associated warmer, dryer microclimate) (Grimm et al., 1994). RLEM are well-known to prefer moist, vegetated habitats (Ridsdill-Smith, 1997), with mites exhibiting lowest mortality at 100\% relative humidity (Solomon, 1937). Mites develop most rapidly at temperatures around $28^{\circ} \mathrm{C}$, with the rate of 
development decreasing towards both higher and lower temperatures (James \& O’Malley, 1991). There have been numerous published studies on RLEM plant hosts (Gaull \& Ridsdill-Smith, 1997; Umina \& Hoffmann, 2004), with no significant impacts on mite development times reported. Competitive interactions between RLEM and other earth mites also change with climatic conditions (Weeks \& Hoffmann, 2000).

The aim of this study was to assess whether regional differences in chemical usage, and climatic conditions affecting voltinism and the distribution/abundance of RLEM, could explain spatial patterns in the occurrence of pyrethroid resistance. Specifically, we hypothesised 1) chemicals applied during the periods when mites are active (i.e. outside of the summer diapause period) would be positively associated with resistance; 2) climatic conditions more suitable for RLEM (cooler, wetter regions) would be associated with a greater abundance of mites and thus more genetic variation for resistance to develop; 3) similarly, differences in land usage and associated host plants would affect abundance due to known host-plant preferences; and 4) conditions favouring faster generation turnover (optimal development temperatures) and a longer RLEM active season (early season rain and long growing season) would speed up the evolution of resistance. These hypotheses cannot be considered in isolation as the underpinning processes are linked. For example, pesticide usage is likely to be linked to climatic factors that increase abundance and voltinism. This is an inherent weakness of correlational studies; however, we attempt to minimise the effect of potentially interacting processes by ensuring predictor variables are not highly correlated, and through the inclusion of land usage data, likely to be a more important driver of pesticide usage than climate (recognising higher value crops experience higher pesticide inputs to mitigate the risk of pest damage). In this study, we apply an increasingly used method for the analysis of complex categorisation problems: boosted-regressiontree models (a special case of generalized boosted models). Boosted-regression-tree models have been applied to other areas of high economic importance, such as in the fields of epidemiology (Friedman \& Meulman, 2003; Dhingra et al., 2014) and biosecurity (Catford et al., 2011; Compton et al., 2012), but, to our knowledge, this is the first application to resistance management issues. 


\section{Methods}

Pyrethroid resistance occurrence data

Joint resistance monitoring efforts supported by the Australian Grains Research and Development Corporation have resulted in a dataset of 722 unique RLEM populations spanning 2007-2015 for which field resistance has been measured. This spans the distribution of RLEM across southern Australia. Pyrethroid resistant individuals are approximately 250,000 times more resistant to bifenthrin when compared with susceptible mites (Umina, 2007). This high degree of resistance allows for the separation of resistant individuals from susceptible ones through exposure to a range of discriminating doses of bifenthrin (e.g. 0.1 or $100 \mathrm{mg} \mathrm{L}^{-1}$ ). In this study, we used distribution data of resistance previously published by Umina et al. (2012) and Umina et al. (2017), as well as unpublished data gathered over multiple years (P. Umina, unpubl. data). This data has been obtained by undertaking pesticide laboratory bioassays employing a glass vial technique as described in detail by Hoffmann et al. (1997). Of the 722 data points included in this study, 659 resulted from screening collected H. destructor populations at either $0.1 \mathrm{mg}$ a.i. $\mathrm{L}^{-1}$ (which is roughly the $\mathrm{LC}_{90}$ value multiplied by 2 ) or a higher rate (100 $\mathrm{mg}$ a.i. $\left.\mathrm{L}^{-1}\right)$, as per the approach used by Umina et al. (2012). In all bioassays, a control of water was used, and a known susceptible mite population was included as a comparison. The remaining 63 mite populations were screened using a molecular diagnostic designed to detect a modification at the $k d r$ gene that is tightly associated with bioassay survival and known to confer resistance to pyrethroid chemicals (Edwards et al. forthcoming; see supplementary information). Approximately 100 mites were used in both the pesticide bioassay and genetic screening approaches.

For the purposes of this analysis, any detection of resistance has been defined as 'field-evolved resistance' - a genetically based decrease in the susceptibility to a pesticide in a population caused by exposure to the pesticide in the field (following Tabashnik et al., 2014). Thus, a mite population was deemed to be 'resistant' if there was some level of pyrethroid resistance detected, regardless of the proportion of individual mites found to have resistance (i.e. even 1 in 100 screened individuals). The analysis was conducted at the 0.05 -degree resolution (approximately $\sim 5 \mathrm{~km}$ ). If any survey within 
each 0.05-degree grid cell detected resistance, then pyrethroid resistance was considered present within that grid cell. This resulted in a total of 413 cells with resistance information (101 resistant and 312 susceptible cells) being included in the analysis.

Land usage data

The spatial distribution of agricultural land use at the 0.01-degree resolution for the 2005-6 and 201011 periods were derived from Advanced Very High Resolution Radiometer (AVHRR) satellite imagery (Australian Bureau of Agricultural and Resource Economics - Bureau of Rural Sciences (ABARE-BRS), 2014). Older available data on land usage was not used (e.g. 2000-2001) due to incongruities in land use categories, which were specified at a coarser level (e.g. no distinction between summer or winter cereals). The estimated type and abundance of agricultural land use was further restricted by agricultural census data (Australian Bureau of Statistics (ABS), 2012). Land use

was reported as falling into one of 26 categories as specified by the Australian Land Use and Management (ALUM) Classification (Bureau of Agricultural and Resource Economics and Sciences, 2010). The most common land usage within each 0.05 -degree grid cell (of the 25 constituent 0.01 degree grid cells) was used in the analysis. Details of the land usage data can be found in the supplementary information.

Chemical usage data

Chemical usage across Australia (Fig. 1) was estimated through the combination of two data sets: 1) gridded data on estimated land usage in Australia for the periods 2010-11 and 2005-2006; and 2) survey data detailing the paddock histories and chemical applications of Australian growers $(\sim 1000$ spray histories from nearly 200 unique locations, spanning years 2009 to 2014). As land use categories for gridded data and survey data did not correspond exactly, remapping of categories was required. We used mean chemical application rates from paddocks labelled in survey data as 'pasture', 'vetch', 'lucerne' and 'ryegrass' to estimate usage for the ALUM category 'grazing sown pastures' and 'pasture for hay or seed', paddocks labelled 'wheat', 'barley', 'cereal' and 'oats' in the survey data to estimate usage for the ALUM category 'winter cereals', while paddocks labelled 'lupin' and 
'canola' to estimate usage for the ALUM categories 'winter legumes' and 'winter oilseeds', respectively. Due to insufficient chemical data on other ALUM land usage categories, pyrethroid usage was assumed negligible in other land usage types. As farming practices differed between regions, Western Australian survey data on chemical usage was analysed separately to other Australian states, which were pooled due to data availability. Land-usage data (available at the 0.01degree resolution) allowed the estimate of pesticide usage to be an aggregated approximation of usage across a region (i.e. 25 cells aggregated per 0.05 -degree cell), which captured the effect of multiple land uses within a region (i.e. prevailing crop rotations).

Climatic data

As a proxy for processes affecting long-term abundance and distribution of RLEM, climatic variables were chosen based on a recent study on RLEM niche shifts using a MAXENT modelling approach (Hill et al., 2013). Hill et al. (2013) used a subset (temperature seasonality, winter temperature, and the amount of rainfall in the warmest and coolest quarter of the year) of the 19 primary BIOCLIM variables (Booth et al., 2014) in combination with a CGIAR-CSI Global-Aridity index (Zomer et al., 2008), to successfully describe past, and present distributions of RLEM in both Australia and their native range of South Africa. The BIOCLIM variables were obtained from the WorldClim database (Hijmans et al., 2005), which are derived from average monthly (1950-2000) temperature and precipitation data. The variables describe means, trends and seasonal variations of temperature and precipitation, which are more likely to represent physiological limits for species (Graham \& Hijmans, 2006). The global aridity index was calculated as the mean annual precipitation divided by the mean annual potential evapo-transpiration and therefore represents precipitation availability over atmospheric water demand (Zomer et al., 2008). These environmental correlates (Table 1) conform with what is known about the biology of RLEM, which prefer cool, moist environments while active (Solomon, 1937), but are able to tolerate hot, dry summer conditions as diapause eggs (Wallace, 1970).

Voltinism 
To estimate voltinism (number of generations per year) we applied general methods to first calculate: 1) the cessation of diapause in autumn; 2) the commencement of diapause in spring; and 3) the temperature response of lifecycle duration so that the number of generations can be predicted between these two timepoints. The onset of diapause was estimated using a model developed in 2005, which predicts the date of $90 \%$ diapause from daylength and long-term growing season (Ridsdill-Smith et al., 2005). This tool is widely used across Australia to effectively time chemical applications in spring (i.e. before mites have laid diapause eggs). The cessation of diapause was estimated using a recently developed model for predicting the timing of RLEM egg hatches across Australia from a combination of cumulative rainfall and cold temperatures (McDonald et al., 2015). Finally, lifecycle duration was estimated to require 5 weeks to complete at a temperature cycle of $10 \mathrm{~h}$ at $18^{\circ} \mathrm{C}, 14 \mathrm{~h}$ at $11^{\circ} \mathrm{C}$ (RidsdillSmith \& Gaull, 1995), which was adjusted for temperature using Boltzmann-Arrhenius equation with inhibition at temperatures under $4^{\circ} \mathrm{C}$ and over $30^{\circ} \mathrm{C}$ based on developmental rate data (James \& O'Malley, 1991). Gridded data on daily climatic conditions was derived from 20 -year averages of climatic data from the Australian Bureau of Meteorology.

Modelling approach

The boosted-regression-tree (BRT) approach is a machine learning technique used for classification problems that produces a prediction from an ensemble (boosting) of many weaker models (decision trees) (Friedman, 2002; Elith et al., 2008). Models are added to the ensemble iteratively based on the optimisation of a loss function - usually some measure of predictive deviance. Overfitting is reduced by a process called bagging, whereby each model added to the ensemble is fitted to a randomly sampled (with replacement) subset of data. Predictions based on an ensemble of many simple models with a probabilistic component are usually more stable and accurate than those based on single decision trees (Elith et al., 2008). We chose a bagging size of 0.5, which is appropriate for smaller data sets (Friedman, 2002) and implemented the model in R using code provided by Elith et al. (2008). A k-fold cross-validation procedure was used to train (90\%) and test (10\%) each model, whereby the data is randomly divided into 10 subsets, with each subset sequentially omitted from the training process and used to test the model predictions. A learning rate of 0.001 was used resulting in a model 
with 2450 trees. The relative contribution of each predictor variable to the model was estimated using a standard practice (Friedman, 2002; Elith et al., 2008) whereby the importance is proportional to the frequency with which a variable is selected for splitting, weighted by the squared improvement to the individual tree as a result of each split, and averaged over all trees. Following Elith et al. 2008, if the omission of a predictor variable did not significantly impact the model (predictive deviance \pm standard error from 10-fold cross-validation interval included the predictive deviance of the full model) it was excluded. Pair-wise Pearson's correlation coefficients of predictor variables were evaluated to ensure no predictor variables were collinear. Coefficients higher than 0.8 were considered to indicate high correlation (Lozier \& Mills, 2009; Hill et al., 2013). Interactions between predictors are automatically captured in a BRT model if supported by the data, with the dimension of the interaction set by the depth of the tree (e.g. a tree with 5 branches can theoretically capture a 5dimensional interaction). Pairwise interaction strength can be examined by estimating model predictions for a grid of values for each pair of predictors (with all other predictors held at their mean level) and linearly regressing this grid against the two predictors (treated as categorical variables without interaction). This method essentially identifies deviations of the BRT model predictions from linear combinations of each predictor pair, which can be used as a measure of interaction strength. No significant interactions were identified in the data set, with the relative strength of interactions detailed in the supplementary information.

\section{Results}

Our spatial model accurately predicted the evolution of pyrethroid resistance, achieving a receiver operating characteristic (ROC) score of 0.96 for the training data and 0.83 for the cross-validation (cv) data set. The mean total deviance and residual deviance of the model was 1.11 and 0.56 , respectively. While there was some correspondence between estimated chemical usage and the occurrence of resistance (Fig. 2), the importance of climatic variables in the model suggest that climate, in addition to chemical usage, must be considered in explaining the evolution of resistance in RLEM. In particular, summer precipitation contributed the most to the model performance (24.9\%), with 
selection pressure contributing $17.8 \%$ (Table 1). The analysis identified conditions and locations associated with a high certainty of resistance (Fig. 2 and 3). A threshold effect was observed for rainfall in the warmest quarter whereby rainfall greater than $60 \mathrm{~mm}$ per quarter was associated with a lower risk of resistance. Temperature seasonality contributed $17.0 \%$ to the model, with resistance associated with low seasonality (i.e. small variation in monthly mean temperatures). As expected, low selection pressure was associated with the lowest risk of resistance, but the risk did not increase in a positive monotonic relationship, as shown in the multi-modal partial-dependence plot (Fig. 2). The aridity index contributed $17.1 \%$ to model performance, with intermediate values of around 0.8 most associated with resistance. Voltinism contributed $12.7 \%$ to the model, with a positive functional response as expected, while winter precipitation contributed $10.5 \%$, with resistance associated with moderate rainfalls. After fitting a model with all predictor variables described in Table 1, modelsimplification eliminated predictor variables for rainy season temperature and both land usage variables.

To identify other areas of high predicted risk of pyrethroid resistance, the fitted model was projected across Australia to areas without observations (Fig. 3). Within Western Australia, the south-western region was identified as a location not presently known to contain resistant populations, but estimated as highly suitable to resistance evolution. Outside of Western Australia, where resistance has not been observed, the model predicts some coastal areas of southern-eastern Australia to be most at risk.

\section{Discussion}

In contrast to a decade ago, pyrethroid resistance in RLEM is now found across many regions in Western Australia ( $c f$ Umina, 2007). However, these locations are not a random subset of the occupied species range. Our findings indicate there is a strong environmental signature in the spatial pattern of resistance; this can be related to variables associated with selection pressure, voltinism, and abundance. In addition to increasing our understanding of the potential drivers in the evolution of resistance, our approach highlights regions with conditions most favourable to the future evolution of resistance. Our findings suggest that resistance management in other pest species may be improved 
through methods that incorporate climate and ecology, in addition to pesticide usage. Boostedregression-tree models are an established tool in ecology, having made large contributions to difficult presence/absence problems such as understanding species distributions. We have shown here that these models have the potential to contribute significantly to understanding the distribution and drivers of pesticide resistance - an increasingly important problem in agricultural systems.

Selection pressure was estimated from land usage patterns and corresponding average chemical practices. The resulting pyrethroid usage layer accounted for broad regional differences in application rates (due to differences in land usage and prevailing chemical practices), which may help to explain why pyrethroid resistance in RLEM has not yet been detected in eastern states. However, within Western Australia, areas of the highest estimated chemical application rates did not necessarily correspond to areas where resistance is most prevalent (Fig. 1). This finding is also evident in the predicted functional response of pyrethroid usage (Fig. 2), which counter-intuitively declines at higher rates. This may be due to several factors. Firstly, chemical application rate was estimated at a coarse resolution (land usage at 0.01-degrees aggregated to 0.05-degree grid cells), reflecting limitations in satellite derived data. Secondly, chemical usage was assumed to only depend on the land usage type and broad geographic region (i.e. Western Australia and eastern Australia), and did not take into account fine-scale regional variation, as would be expected to exist due to individual management decisions and cultural factors determining local practices (Pannell et al., 2006). Thirdly, the chemical layer alone does not reflect how environmental variables will affect mite numbers, and thus the requirement for chemical control, which is discretionary. Fourthly, the rate of resistance development is not necessarily related to chemical usage directly given that intermediate levels of chemical usage can lead to more rapid evolution of resistance than high or low levels (Shaw, 2000). Despite these limitations, estimated chemical application was found to be a strong contributor to the model (Table 1), with higher levels of chemical application, in general, leading to more resistance compared with low levels. But the large contribution of climatic variables to the model highlights the importance of considering other environmental drivers in the evolution of resistance. 
Despite resistance currently being restricted to Western Australia, our model predicted areas within eastern Australia that are at highest risk of developing pyrethroid resistance. As many of these locations have not yet been screened for insecticide resistance (Fig. 1), it is possible that resistance has already developed, but remains at levels lower than that required for chemical control failures to be detected. These predictions will be useful to ongoing monitoring and extension efforts surrounding the prioritisation of future resistance surveillance and education programs.

The shape of the response curves of climatic predictors in this study were broadly similar to that found in a study that modelled the distribution of RLEM (Hill et al., 2012), despite being based on a unique data set (resistance data, rather than species distribution data). Similarity in response curves may be unsurprising given that variables associated with higher habitat suitability are consistent with eco-physiological knowledge on RLEM (Ridsdill-Smith, 1997) and are also likely to be associated with both a higher requirement for chemical control and a higher standing genetic variation.

Although there are similarities between the climatic responses of resistance and distribution models, the exception to this was the effect of temperature seasonality. In the distribution model of Hill et al. (2012), increased temperature seasonality was associated with a higher presence of mites, while the opposite was found here for resistance. This may relate to the increased ability to control mites with a single chemical application in more seasonal environments (Ridsdill-Smith et al., 2005; Gower et al., 2008; Ridsdill-Smith \& Pavri, 2015). Ridsdill-Smith et al. (2015) hypothesised that chemical control was less effective in eastern Australian populations of RLEM due to the more variable spring and early summer conditions, compared with the more Mediterranean climate of Western Australia. If correct, this implies that more variable climatic conditions lead to less synchronised mite populations and less control per pesticide application, which may result in higher chemical doses to achieve a given level of control and, consequently, greater selection pressure. Indeed, as part of a recently developed national resistance management strategy for RLEM, multiple applications of a single chemical class within a season were strongly advised against due to the associated increase in selection pressure for resistance, in part due to overlapping generations (Umina et al., 2016). 
In this study, we hypothesised differences in land usage would be an important predictor of resistance due to potential effects on mite abundance and management practices (e.g. mites prefer, and are more abundant, in pasture compared with canola, but canola tends to receive more frequent pesticide applications than pasture due to its higher value per land area). However, land usage contributed little to the model and was subsequently removed in the process of model simplification. This may be due to the effect of climate being relatively more important in determining properties of mite populations. However, as detailed in the supplementary information, land usage categories are coarse (e.g. winter cereals include oats, barley and wheat) and in some cases, are incomplete (e.g. 37 of 412 cells were classed as 'non-agricultural land or no data'). Finer variation within categories may lead to a stronger signature of land use on resistance.

The modelling approach used did not include migration processes due to the limited ability of RLEM to disperse (Weeks et al., 2000), and the discovery of multiple resistance evolution events. However, when dealing with pests where dispersal is clearly very important to resistance evolution (e.g. Bass et al., 2014), the model would benefit from the explicit inclusion of migration processes. Furthermore, our approach is based on correlation between variables, and thus only indirectly links to processes driving resistance evolution. An attempt was made to ensure more proximate variables affecting the evolution of resistance were derived from less proximate variables (e.g. voltinism rather than daily temperatures). A more mechanistic approach could be undertaken to further understand processes leading to resistance evolution. Mechanistic models tend to outperform correlative approaches when predicting into novel scenarios (Maino et al., 2016). This minimises the risk of unrealistic predictions, such as when resistance is predicted to occur in locations with no estimated chemical usage but due to the correlative contribution of other variables in the model. The main trade-off with mechanistic approaches is they require an in-depth knowledge of the components relevant to predicting a particular system. In the case of RLEM, important biological knowledge, such as the drivers of seasonal abundance (Ridsdill-Smith \& Annells, 1997) and the mechanisms conferring resistance (e.g. acquired insensitivity to a chemical or enhanced detoxification (Roush \& Tabashnik, 1990)), has only been partially resolved. This highlights a key strength of the approach used here, which allows for 
imperfect biological knowledge to formulate predictions, and to generate hypotheses of the drivers of resistance. Such predictions can be tested under more controlled conditions, such as through simulation or experimental approaches, and should ultimately lead into improved pest management practices.

\section{Acknowledgements}

The authors would like to acknowledge funding support from the Grains Research and Development

Corporation. We would also like to thank Jane Elith and two anonymous reviewers for useful comments on this manuscript. Insecticide resistance and historical paddock history data for RLEM were generated by numerous researchers, including Svetlana Micic, Peter Mangano, Alan Lord and Owain Edwards.

\section{Data accessibility statement}

Upon acceptance, data supporting the results will be archived in an appropriate public repository such as Dryad or Figshare and the data DOI will be included at the end of the article, except data

containing sensitive information, such as GPS locations of private properties.

\section{Biosketch}

James Maino is an ecological modeller utilising mathematics, theoretical biology, and computational simulations to predict life-histories, distributions, and abundances of invertebrates. Much of this work involves the incorporation of ecophysiological knowledge into process-based predictive models.

Paul Umina is an agricultural scientist specialising in entomology. Early in his career he conducted one of the first studies demonstrating how genetic markers in insects can be used to monitor climate change. His work was integral to the discovery of insecticide resistance in the redlegged earth mite, one of Australia's most significant agricultural pests.

Ary Hoffmann works in the areas of pest control and environmental stress adaptation, undertaking research on a range of invertebrates. His group have developed integrated pest control options for the 
grains and grape/wine industries, investigated how landscape changes can be harnessed to provide pest control services, contributed to novel approaches for suppressing dengue mosquito vectors, and examined new ways to predict species distribution shifts under climate change.
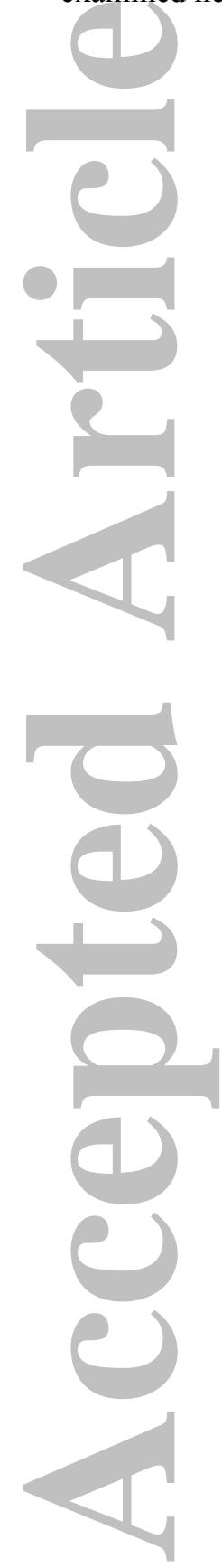


\section{References}

Australian Bureau of Agricultural and Resource Economics - Bureau of Rural Sciences (ABARE-

BRS) (2014) User Guide and Caveats: Land Use of Australia, Version 5 2010-11.

Australian Bureau of Statistics (ABS) (2012) 7121.0 - Agricultural Commodities, Australia, 2010-11, ABS, Canberra.

Bass, C., Puinean, A.M., Zimmer, C.T., Denholm, I., Field, L.M., Foster, S.P., Gutbrod, O., Nauen, R., Slater, R. \& Williamson, M.S. (2014) The evolution of insecticide resistance in the peach potato aphid, Myzus persicae. Insect Biochemistry and Molecular Biology, 51, 41-51.

Booth, T.H., Nix, H.A., Busby, J.R. \& Hutchinson, M.F. (2014) Bioclim: The first species distribution modelling package, its early applications and relevance to most current MaxEnt studies.

Diversity and Distributions, 20, 1-9.

Bureau of Agricultural and Resource Economics and Sciences (2010) The Australian Land Use and Management (ALUM) Classification Version 7, May 2010. 16.

Catford, J.A., Vesk, P.A., White, M.D. \& Wintle, B.A. (2011) Hotspots of plant invasion predicted by propagule pressure and ecosystem characteristics. Diversity and Distributions, 17, 1099-1110.

Compton, T.J., De Winton, M., Leathwick, J.R. \& Wadhwa, S. (2012) Predicting spread of invasive macrophytes in New Zealand lakes using indirect measures of human accessibility. Freshwater Biology, 57, 938-948.

Dhingra, M.S., Dissanayake, R., Negi, A.B., Oberoi, M., Castellan, D., Thrusfield, M., Linard, C. \& Gilbert, M. (2014) Spatio-temporal epidemiology of highly pathogenic avian influenza (subtype H5N1) in poultry in eastern India. Spatial and Spatio-temporal Epidemiology, 11, 45-57.

Elith, J., Leathwick, J.R. \& Hastie, T. (2008) A working guide to boosted regression trees. Journal of Animal Ecology, 77, 802-813.

Feng, R. \& Isman, M.B. (1995) Selection for resistance to azadirachtin in the green peach aphid, 
Myzus persicae. Experientia, 51, 831-833.

Friedman, J.H. (2002) Stochastic gradient boosting. Computational Statistics and Data Analysis, 38, $367-378$.

Friedman, J.H. \& Meulman, J.J. (2003) Multiple additive regression trees with application in epidemiology. Statistics in Medicine, 22, 1365-1381.

Gaull, K.R. \& Ridsdill-Smith, T.J. (1997) Host Plant Acceptance by Redlegged Earth Mite, Halotydeus destructor ( Tucker ) ( Acarina : Penthaleidae ). Journal of Insect Behavior, 10, 859869.

Georghiou, G.P. \& Taylor, C.E. (1977) Genetic and biological influences in the evolution of insecticide resistance. Journal of Economic Entomology, 70, 319-323.

Gower, J.M.C., Hoffmann, A.A. \& Weeks, A.R. (2008) Effectiveness of spring spraying targeting diapause egg production for controlling redlegged earth mites and other pests in pasture. Australian Journal of Experimental Agriculture, 48, 1118-1125.

Graham, C.H. \& Hijmans, R.J. (2006) A comparison of methods for mapping species ranges and species richness. Global Ecology and Biogeography, 15, 578-587.

Grimm, M.A., Hyder, M.B., Doyle, P.B. \& Michael, P.C. (1994) The effect of pasture feed on offer in spring on pest populations and pasture production. Proceedings of the Australian Society of Animal Production, 20, 233-236.

Hijmans, R.J., Cameron, S.E., Parra, J.L., Jones, P.G. \& Jarvis, A. (2005) Very high resolution interpolated climate surfaces for global land areas. International Journal of Climatology, 25, $1965-1978$.

Hill, M.P., Chown, S.L. \& Hoffmann, A.A. (2013) A predicted niche shift corresponds with increased thermal resistance in an invasive mite, Halotydeus destructor. Global Ecology and Biogeography, 22, 942-951. 
Hill, M.P., Hoffmann, A.A., MacFadyen, S., Umina, P.A. \& Elith, J. (2012) Understanding niche shifts: Using current and historical data to model the invasive redlegged earth mite, Halotydeus destructor. Diversity and Distributions, 18, 191-203.

Hoffmann, A.A., Porter, S. \& Kovacs, I. (1997) The response of the major crop and pasture pest, the red-legged earth mite (Halotydeus destructor) to pesticides: Dose-response curves and evidence for tolerance. Experimental \& Applied Acarology, 21, 151-162.

James, D.G. \& O’Malley, K.J. (1991) Effect of temperature on development and survival of eggs of Halotydeus destructor (Tucker) (Acari: Penthaleidae). International Journal of Acarology, 17, $37-41$.

Khodaverdi, H., Fowles, T., Bick, E. \& Nansen, C. (2016) Does Drought Increase the Risk of Insects Developing Behavioral Resistance to Systemic Insecticides? Journal of Economic Entomology, 109, 2027-2031.

Kimball, K.D. \& Levin, S. a. (1985) Limitations of Laboratory Bioassays: The Need for EcosystemLevel Testing. BioScience, 35, 165-171.

Lozier, J.D. \& Mills, N.J. (2009) Ecological niche models and coalescent analysis of gene flow support recent allopatric isolation of parasitoid wasp populations in the Mediterranean. PLoS

ONE, 4.

Maino, J.L., Kong, J.D., Hoffmann, A.A., Barton, M.G. \& Kearney, M.R. (2016) Mechanistic models for predicting insect responses to climate change. Current Opinion in Insect Science, 17, 81-86.

McDonald, G., Umina, P.A., Macfadyen, S., Mangano, P. \& Hoffmann, A.A. (2015) Predicting the timing of first generation egg hatch for the pest redlegged earth mite Halotydeus destructor (Acari: Penthaleidae). Experimental and Applied Acarology, 65, 259-276.

Murray, D.A.H., Clarke, M.B. \& Ronning, D.A. (2013) Estimating invertebrate pest losses in six major Australian grain crops. Australian Journal of Entomology, 52, 227-241.

Pannell, D.J., Marshall, G.R., Barr, N., Curtis, A., Vanclay, F. \& Wilkinson, R. (2006) Understanding 
and promoting adoption of conservation practices by rural landholders. Australian Journal of Experimental Agriculture, 46, 1407-1424.

Patil, N.S., Lole, K.S. \& Deobagkar, D.N. (1996) Adaptive larval thermotolerance and induced crosstolerance to propoxur insecticide in mosquitoes Anopheles stephensi and Aedes aegypti.

Medical and veterinary entomology, 10, 277-282.

Polson, K.A., Brogdon, W.G., Rawlins, S.C. \& Chadee, D.D. (2012) Impact of environmental temperatures on resistance to organophosphate insecticides in Aedes aegypti from Trinidad. Revista Panamericana de Salud Pública, 32, 1-8.

REX Consortium (2013) Heterogeneity of selection and the evolution of resistance. Trends in ecology \& evolution, 28, 110-8.

Ridsdill-Smith, T.J. (1997) Biology and control of Halotydeus destructor (Tucker) (Acarina:

Penthaleidae): a review. Experimental and Applied Acarology, 21, 195-224.

Ridsdill-Smith, T.J. \& Annells, A.J. (1997) Seasonal occurrence and abundance of redlegged earth mite Halotydeus destructor (Acari: Penthaleidae) in annual pastures of southwestern Australia. Bulletin of Entomological Research, 87, 413.

Ridsdill-Smith, T.J. \& Gaull, K.R. (1995) An improved method for rearing Halotydeus destructor (Acari: Penthaleidae) in the laboratory. Experimental and Applied Acarology, 19, 337-345.

Ridsdill-Smith, T.J., Hoffmann, A.A., Mangano, G.P., Gower, J.M., Pavri, C.C. \& Umina, P.A. (2008) Strategies for control of the redlegged earth mite in Australia. Australian Journal of Experimental Agriculture, 48, 1506-1513.

Ridsdill-Smith, T.J., Pavri, C., De Boer, E. \& Kriticos, D. (2005) Predictions of summer diapause in the redlegged earth mite, Halotydeus destructor (Acari: Penthaleidae), in Australia. Journal of Insect Physiology, 51, 717-726.

Ridsdill-Smith, T.J. \& Pavri, C.C. (2015) Controlling redlegged earth mite, Halotydeus destructor (Acari: Penthaleidae) with a spring spray in legume pastures. Crop and Pasture Science, 66, 
938-946.

Roush, R.T. \& Tabashnik, B.E. (1990) Pesticide resistance in arthropods, Springer Science \& Business Media, Berlin.

Shaw, M.W. (2000) Models of the Effects of Dose Heterogeneity and Escape on Selection Pressure for Pesticide Resistance. Analytical and Theoretical Plant Pathology, 90, 333-339.

Sloane Cook \& King PTY LTD (1989) The Economic Impact of Pasture Weeds, Pests \& Diseases on 1 the Australian Wool Industry: A Report, Australian Wool Corporation, Melbourne.

Solomon, M.E. (1937) Experiments on the effects of temperature and humidity on the survival of Halotydeus destructor (Tucker), Acarina fam. Penthaleidae. Australian Journal of Experimental Biology \& Medical Science, 15, 1-16.

Sparks, T.C. \& Nauen, R. (2015) IRAC: Mode of action classification and insecticide resistance management. Pesticide Biochemistry and Physiology, 121, 122-128.

Stratonovitch, P., Elias, J., Denholm, I., Slater, R., Semenov, M.A. \& Guedes, R.N.C. (2014) An individual-based model of the evolution of pesticide resistance in heterogeneous environments:

Control of Meligethes aeneus population in oilseed rape crops. PLoS ONE, 9, 1-24.

Tabashnik, B.E., Mota-Sanchez, D., Whalon, M.E., Hollingworth, R.M. \& Carrière, Y. (2014) Defining Terms for Proactive Management of Resistance to Bt Crops and Pesticides. Journal of Economic Entomology, 107, 496-507.

Tobin, P.C., Nagarkatti, S., Loeb, G. \& Saunders, M.C. (2008) Historical and projected interactions between climate change and insect voltinism in a multivoltine species. Global Change Biology, 14, 951-957.

Umina, P.A. (2007) Pyrethroid resistance discovered in a major agricultural pest in southern Australia: the redlegged earth mite Halotydeus destructor (Acari: Penthaleidae). Pest Management Science, 63, 1185-1190. 
Umina, P.A. \& Hoffmann, A.A. (2004) Plant host associations of Penthaleus species and Halotydeus destructor (Acari: Penthaleidae) and implications for integrated pest management. Experimental and Applied Acarology, 33, 1-20.

Umina, P.A. \& Hoffmann, A.A. (1999) Tolerance of cryptic species of blue oat mites (Penthaleus spp.) and the redlegged earth mite (Halotydeus destructor) to pesticides. Australian Journal of Experimental Agriculture, 39, 621-628.

Umina, P.A., Weeks, A.R., Roberts, J., Jenkins, S., Mangano, G.P., Lord, A. \& Micic, S. (2012) The current status of pesticide resistance in Australian populations of the redlegged earth mite (Halotydeus destructor). Pest Management Science, 68, 889-896.

Umina, P.A., Hoffmann, A.A., McDonald, G., Edwards, O., Mangano, P., Miles, M., Baker, G., Cornwell, G., Powles, S. \& Schellhorn, N. (2016) Science behind the resistance management strategy for the redlegged earth mite in Australian grains and pasture. Grains Research \& Development Corporation.

Umina. P., Lord, A., Micic, S. \& Edwards, O. (2017) Discovery and characterisation of field resistance to organophosphorus chemicals in a major mite pest, Halotydeus destructor. Pest Management Science, 73, 1719-1724.

Wallace, M.M.H. (1970) Diapause in the aestivating egg of Halotydeus destructor (Acari : Eupodidae). Australian Journal of Zoology, 18, 295.

Wallace, M.M.H. \& Mahon, J.A. (1971) The distribution of Halotydeus destructor and Penthaleus major (Acari: Eupodidae) in Australia in relation to climate and land use. Australian Journal of Zoology, 19, 65-76.

Weeks, A.R. \& Hoffmann, A.A. (2000) Competitive interactions between two pest species of earth mites, Halotydeus destructor and Penthaleus major (Acarina: Penthaleidae). Journal of Economic Entomology, 93, 1183-1191.

Weeks, A.R., Turelli, M. \& Hoffmann, A.A. (2000) Dispersal patterns of pest earth mites (Acari: 
Penthaleidae) in pastures and crops. Journal of Economic Entomology, 93, 1415-1423.

Zomer, R.J., Trabucco, A., Bossio, D.A. \& Verchot, L. V. (2008) Climate change mitigation: A spatial analysis of global land suitability for clean development mechanism afforestation and reforestation. Agriculture, Ecosystems and Environment, 126, 67-80.
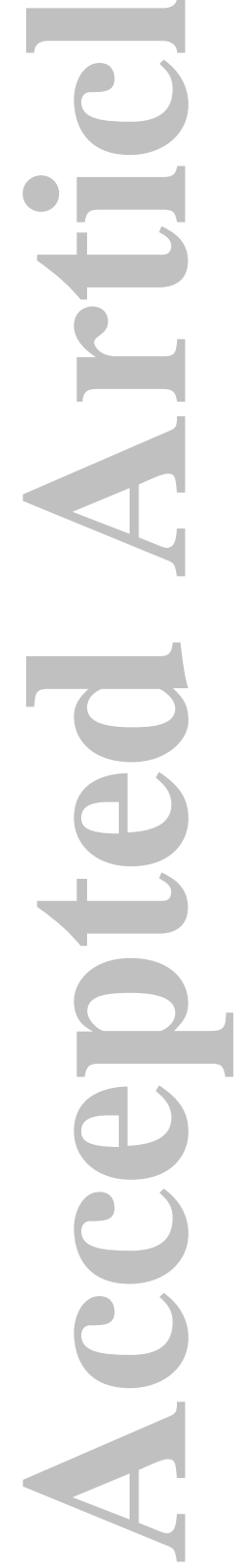


\section{Tables}

\begin{tabular}{ll} 
Table 1. Definitions and relative contributions to model performance (\%) of variables \\
\hline $\begin{array}{l}\text { Predictor Variables } \\
\text { precipitation } \\
\text { (bio_18) }\end{array}$ & $\begin{array}{l}\text { Mean precipitation of warmest quarter } \\
\text { determined to the nearest month in mm of rain }\end{array}$ \\
\hline Selection & $\begin{array}{l}\text { Mean annual number of synthetic pyrethroid } \\
\text { applications based on land usage (ALUM } \\
\text { dataset) and chemical usage (grower surveys). }\end{array}$ \\
\hline & $\begin{array}{l}\text { Mean annual precipitation divided by the mean } \\
\text { annual potential evapo-transpiration. }\end{array}$ \\
\hline $\begin{array}{l}\text { Aridity } \\
\text { Seasonality }\end{array}$ & $\begin{array}{l}\text { Temperature seasonality expressed as the } \\
\text { standard deviation of the monthly mean } \\
\text { temperatures divided by mean of those } \\
\text { temperatures in degrees Kelvin. }\end{array}$ \\
\hline
\end{tabular}

Generations

Number of generations per year, based on estimated development rate, autumn hatch date, and spring diapause date.

\section{Winter} precipitation (bio_19)

$\begin{aligned} & \text { Rainy season } \\ & \text { temperature } \\ & \text { (bio_8*) }\end{aligned}$
Land usage 2005-
06*

Land usage 201011*
Mean precipitation of coolest quarter determined to the nearest month in $\mathrm{mm}$ of rain to the nearest month in degrees Celsius. Most common land usage for each grid cell
during 2005-06 period. during 2010-11 period.

\footnotetext{
* removed from the model after the tree was simplified following Elith et al. (2008)
} 


\section{Figures}

Figure 1.

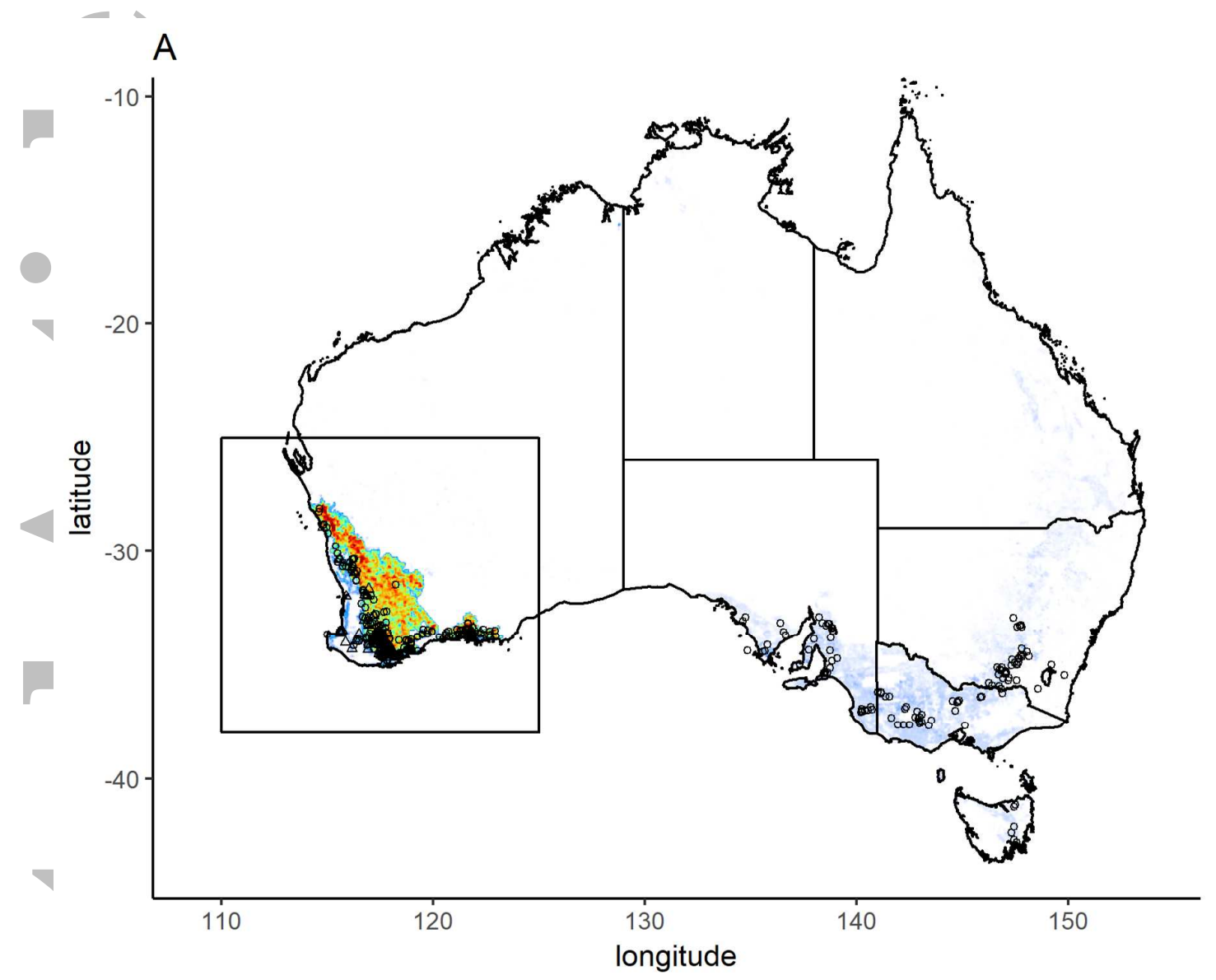




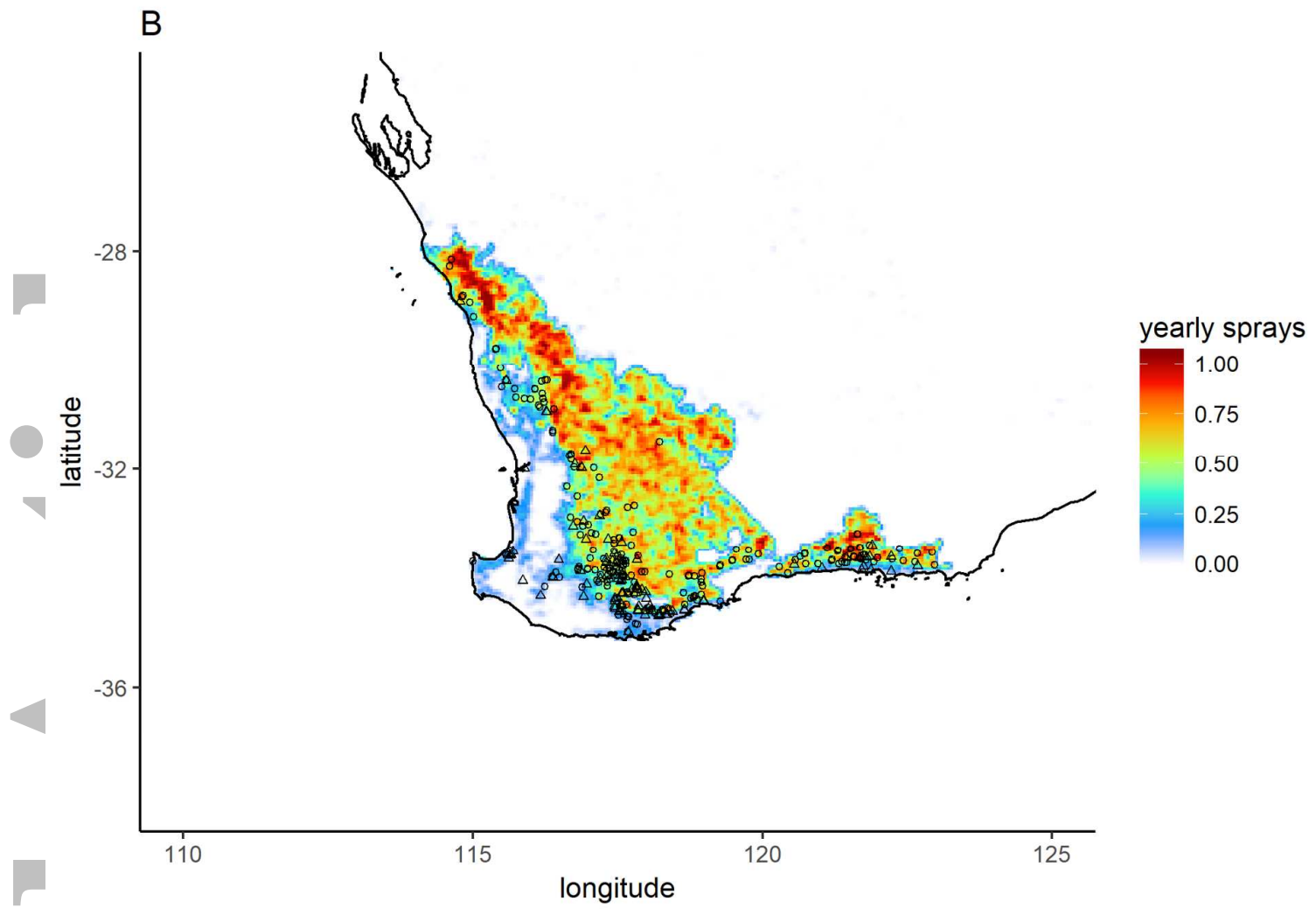

Figure 1. Estimated mean annual application rate of pyrethroids across Australia derived from 201011 and 2005-06 land usage and 2005-14 paddock history data. Usage rates are estimated at (A) a resolution of 0.05 -degrees $(\sim 5 \mathrm{~km})$ for Australia, and (B) a magnified Western Australia region where resistance has been detected. The magnified region is defined by the rectangle in panel A. Populations resistant to pyrethroids are shown as triangles, with circles indicating susceptible mite populations.

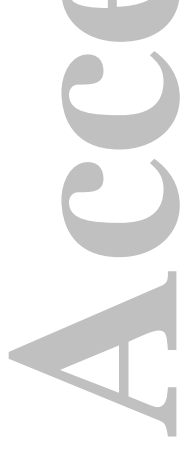


Figure 2.
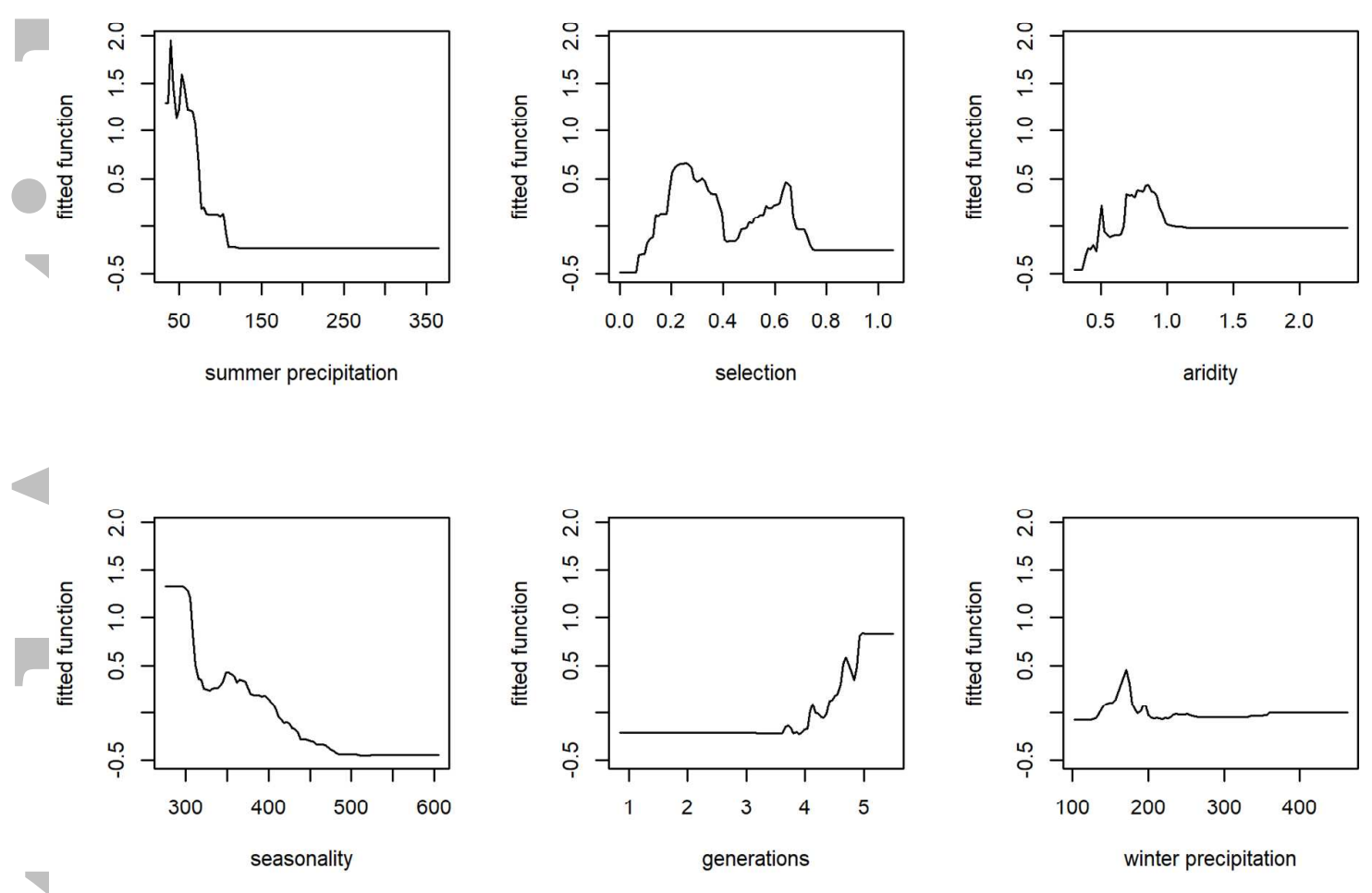

Figure 2. Partial dependency plots for six predictors of resistance as determined from a boostedregression-tree model (other variables fixed at their average values). See Table 1 for a description of predictor variables and their relative contributions. The y axes are logit scale, scaled to have zero mean oyer the data range.

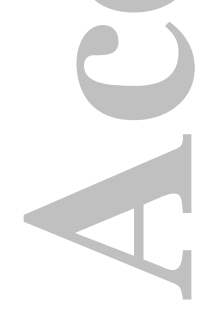


Figure 3.

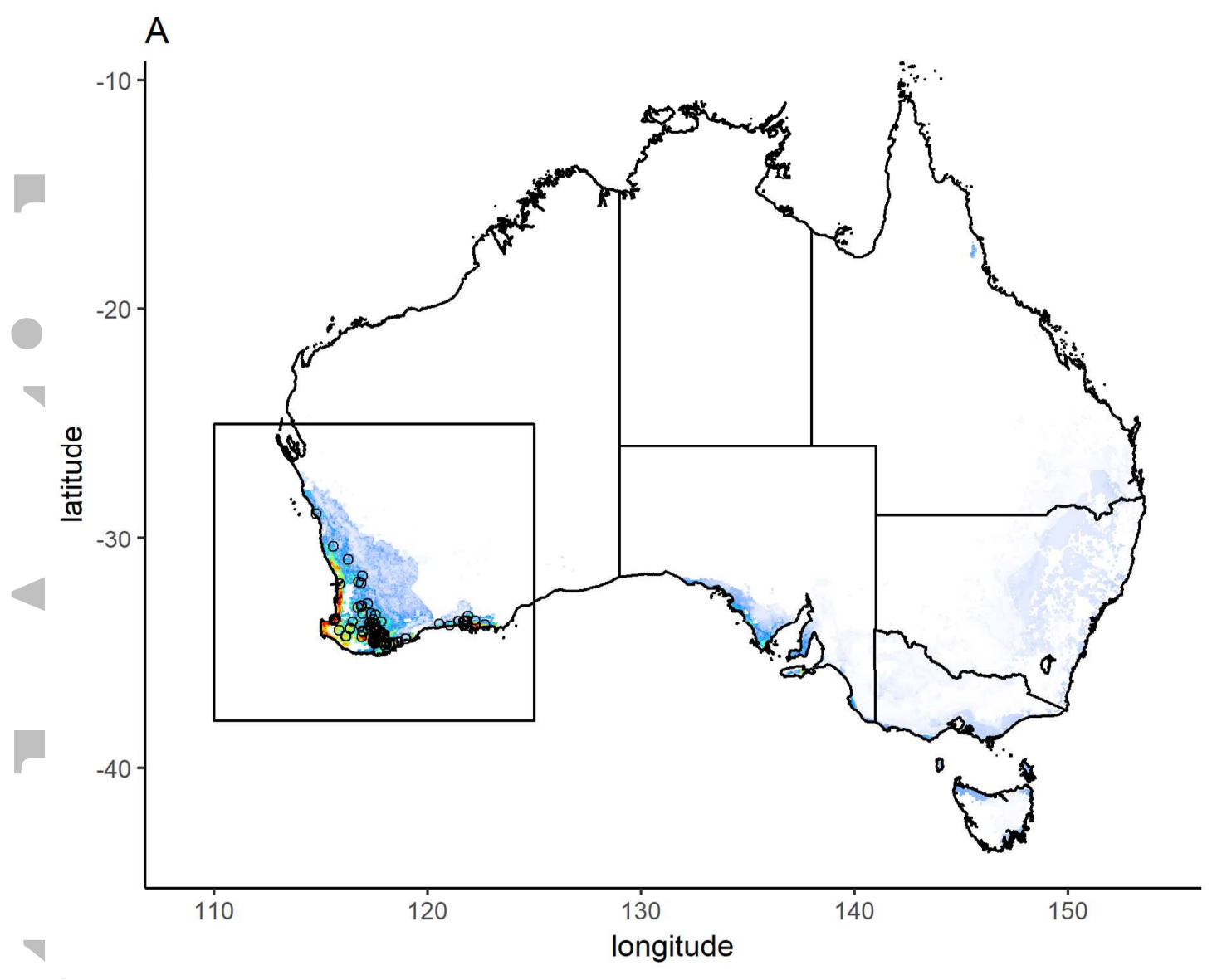




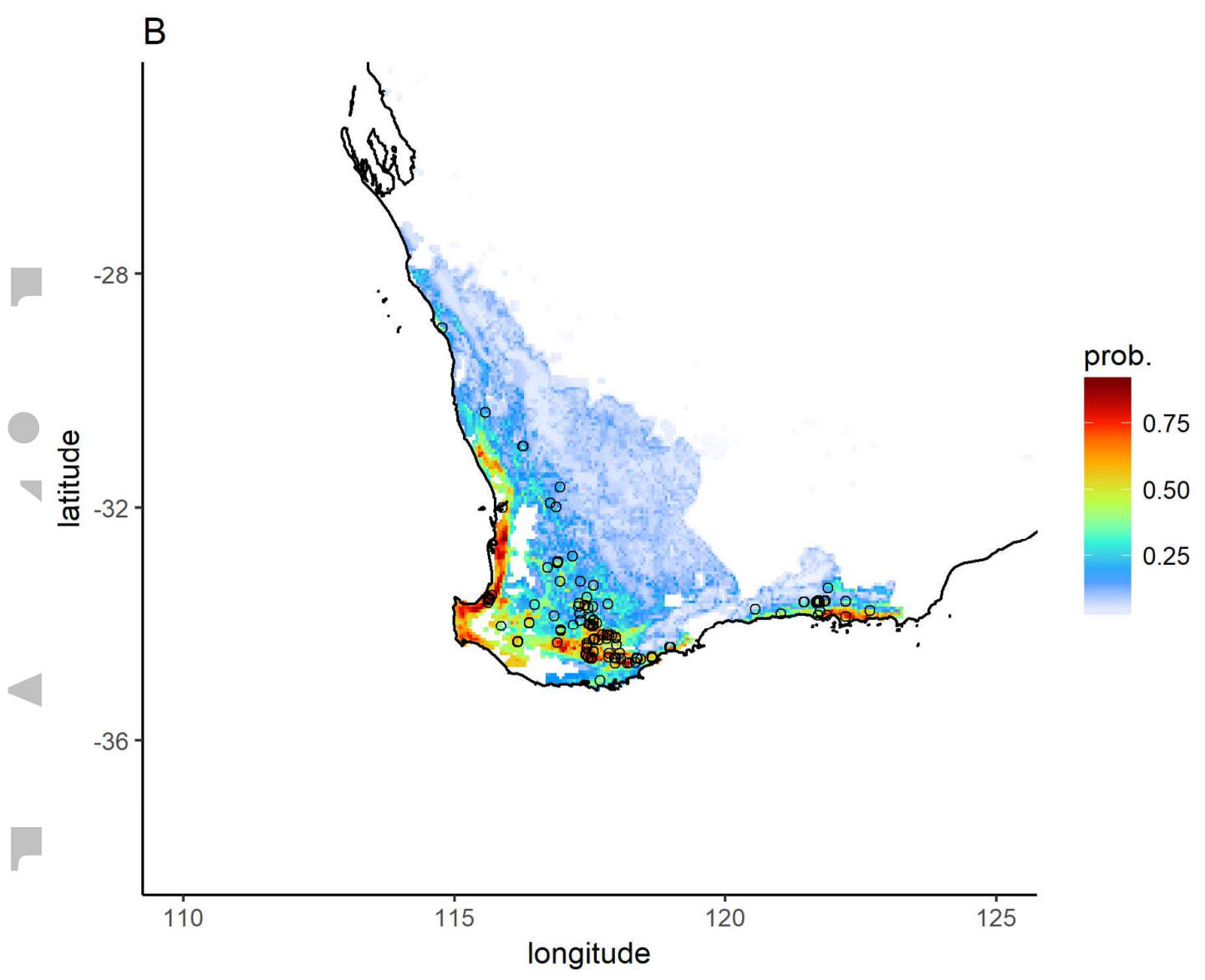

Figure 3. Fitted probability of pyrethroid resistance estimated at (A) a resolution of 0.05 -degrees ( $\sim 5$ $\mathrm{km}$ ) for Australia, and (B) a magnified region of Western Australia where resistance has been detected. The magnified region is defined by the rectangle in panel A. Populations resistant to pyrethroids are shown as open circles. Regions estimated to have no chemical usage and $<1 \%$ occurrence probability were masked.

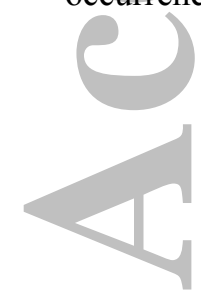




\title{
Supplementary information for Maino et al. 2017 'Climate
}

\section{contributes to the evolution of pesticide resistance'}

\author{
James L. Maino, Paul A. Umina \& Ary A. Hoffmann
}

2

The following text details the construction of each prediction layer used in the boosted-regression-tree analysis for the evolution of pyrethroid resistance in RLEM.

Pyrethroid usage layer

This layer was constructed with the aim of capturing selection pressures for the evolution of pyrethroid resistance in RLEM based on available data on land usage patterns. Land usage data provided by the Australian Collaborative Land Use and Management Program (ACLUMP) was estimated as falling into 1 of 26 categories as specified by the Australian Land Use and Management (ALUM) Classification (Bureau of Agricultural and Resource Economics and Sciences, 2010) for the periods 2005-6 and 2010-11 at the 0.01-degree scale. This was achieved using a combination of Advanced Very High Resolution Radiometer (AVHRR) satellite imagery, and census data (Australian Bureau of Agricultural and Resource Economics - Bureau of Rural Sciences (ABARE-BRS), 2014).

As chemicals are not often applied on non-agricultural land, such as residentially zoned land or conservation reserves, only land uses associated with agricultural production were considered. RLEM are mostly reported in broadacre cropping contexts outside of summer, so the set of land uses was further restricted; for example, RLEM do not affect summer crops such as summer legumes, or summer cereals, so selection pressure in these land use categories was set to zero despite known usage of pesticides. ALUM pasture categories were unable to be separated on this basis, however the survey data showed that the majority ( $>75 \%$ ) of pyrethroid applications occur during the pre-sowing or seedling stage, with the remainder largely comprised of spring sprays, all of which will select for pyrethroid resistance in mites.

Table S1 - Summary of paddock history data spanning 2009-2014 used to convert land usage to pyrethroid spray usage in the eastern states (Eastern) and Western Australia (WA).

\begin{tabular}{|c|c|c|c|c|c|c|c|}
\hline \multirow{2}{*}{$\begin{array}{l}\text { ALUM } \\
\text { land } \\
\text { usage }\end{array}$} & \multirow{2}{*}{$\begin{array}{l}\text { Survey } \\
\text { land } \\
\text { usage }\end{array}$} & \multicolumn{3}{|c|}{ Eastern } & \multicolumn{3}{|c|}{ WA } \\
\hline & & $\begin{array}{c}\text { Spray } \\
\text { Rate }\left(\mathbf{y}^{-1}\right)\end{array}$ & s.e. & $\mathbf{N}$ & $\begin{array}{c}\text { Spray } \\
\text { rate }\left(\mathbf{y}^{-1}\right)\end{array}$ & s.e. & $\mathbf{N}$ \\
\hline $\begin{array}{l}\text { Grazing } \\
\text { sown } \\
\text { pastures } \\
\text { /Pasture }\end{array}$ & $\begin{array}{l}\text { pasture, } \\
\text { vetch, } \\
\text { lucerne, } \\
\text { ryegrass }\end{array}$ & 0.07 & 0.02 & 168 & 0.26 & 0.04 & 325 \\
\hline
\end{tabular}


for hay

seed

\begin{tabular}{llllllll}
\hline $\begin{array}{l}\text { Winter } \\
\text { cereals }\end{array}$ & $\begin{array}{l}\text { wheat, } \\
\text { barley, } \\
\text { oats, } \\
\text { cereal }\end{array}$ & 0.00 & 0.00 & 27 & 1.03 & 0.05 & 388 \\
$\begin{array}{l}\text { Winter } \\
\text { legumes }\end{array}$ & lupin & 0.20 & 0.20 & 5 & 1.17 & 0.17 & 6 \\
\hline $\begin{array}{l}\text { Winter } \\
\text { oilseeds }\end{array}$ & canola & 0.38 & 0.18 & 8 & 1.52 & 0.04 & 234 \\
\hline
\end{tabular}

Additional ALUM categories for which data was lacking or effect on selection assumed negligible included: Agroforestry - newly planted, Apples, Citrus, Cotton, Grapes, Grazing - largely of woodland and open forest, Grazing - native or naturalised pasture or native-exotic pasture mosaic, Non-agricultural land or no data, Nuts, Other non-cereal crops, Pears and other pome fruit, Plantation fruit, Rice, Stone fruit excluding tropical, Sugar cane, Summer cereals excluding rice, Summer legumes, Summer oilseeds, Tropical stone fruit, Unallocated agricultural land, and Vegetables.

While significant effort was made to ensure datasets spanned congruent scales of space and time, we were limited here by patchy survey data that spanned 2009-2014 and ACLUMP data which is reported each $\sim 5$-years (an attempt was made to include some earlier land usage data, but coarser land use categories caused issues). Subsequently, selection pressure for pyrethroid resistance in mites was estimated for 2005-6 and 2010-11 using spray rates for land use types defined in Table S1. These spray rate layers at the 0.01 -degree resolution were aggregated to the 0.05 -degree resolution with the mean taken across both periods resulting in the layer depicted in Fig. S1.

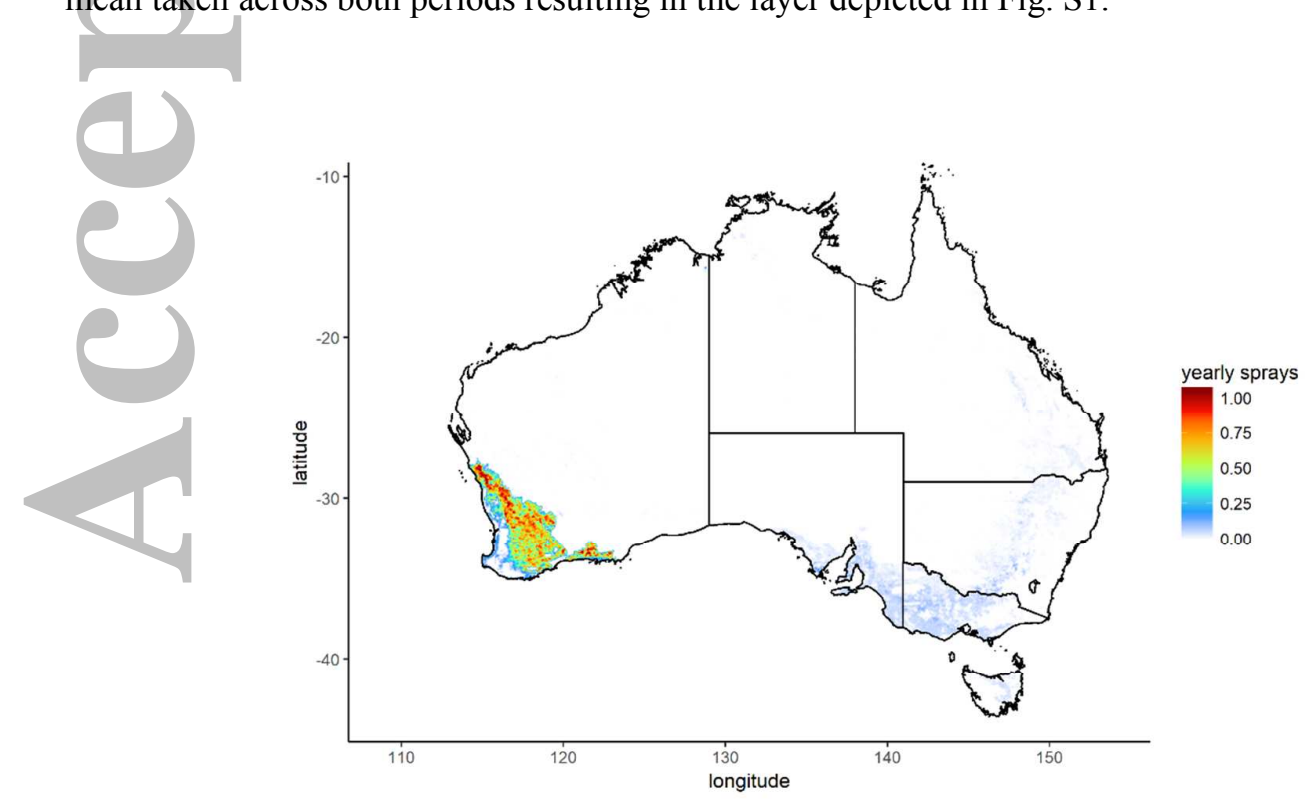

Figure S1. Estimated pyrethroid usage as measured as mean applications per year. 


\section{BIOCLIM layers}

BIOCLIM layers (Booth et al., 2014) are available from online repositories (e.g. https://www.climond.org), which rely on averaged global gridded climatic data spanning 1961-1990 as input data. To make the input climatic data used to construct BIOCLIM layers more congruent with the temporal and spatial dimension of other data layers (e.g. land use data, voltinism), BIOCLIM layers were constructed using monthly averages of daily gridded climatic conditions from 1996-2015 at the 0.05-degree resolution from the Australian Bureau of Meteorology. The function biovars in the $\mathrm{R}$ package dismo was used to generate the BIOCLIM layers at the 0.05-degree resolution after grids for monthly mean conditions had been constructed from the daily data. Figs. S2-S5 plot the BIOCLIM layers used in the analysis presented in the main text.
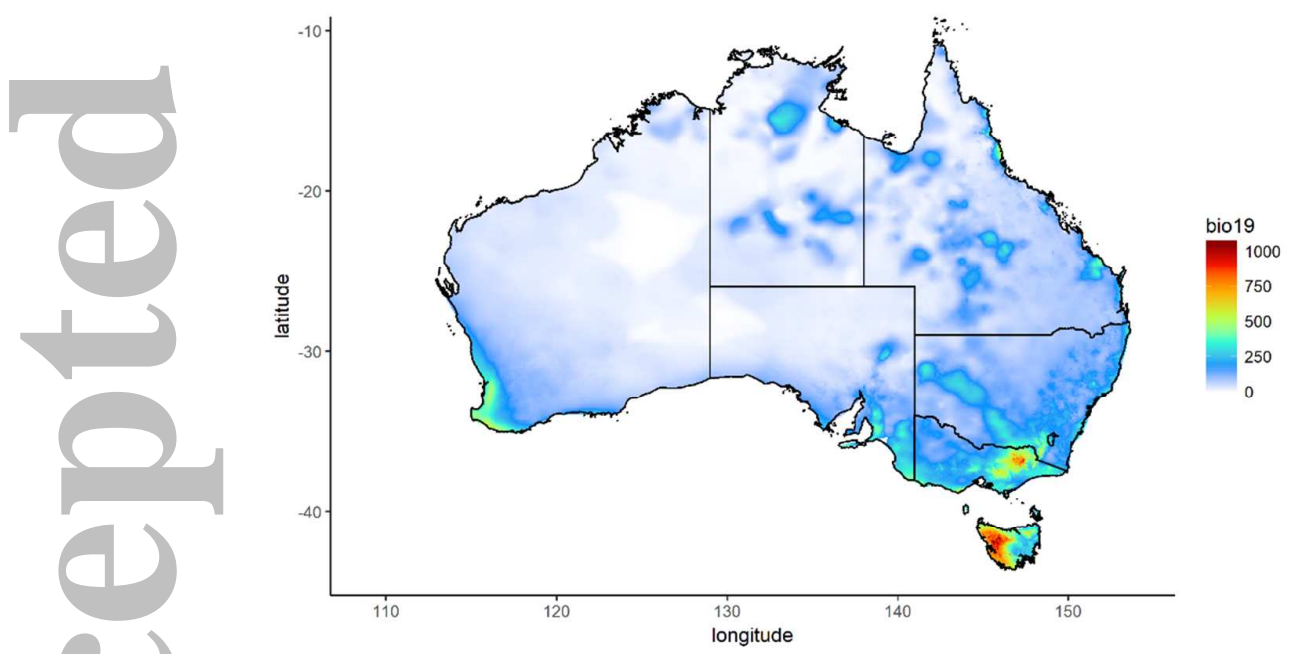

Figure S2. Bio19: Mean precipitation ( $\mathrm{mm}$ ) of coolest quarter determined to the nearest month in mm of rain.

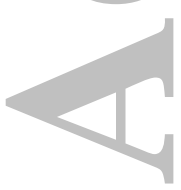




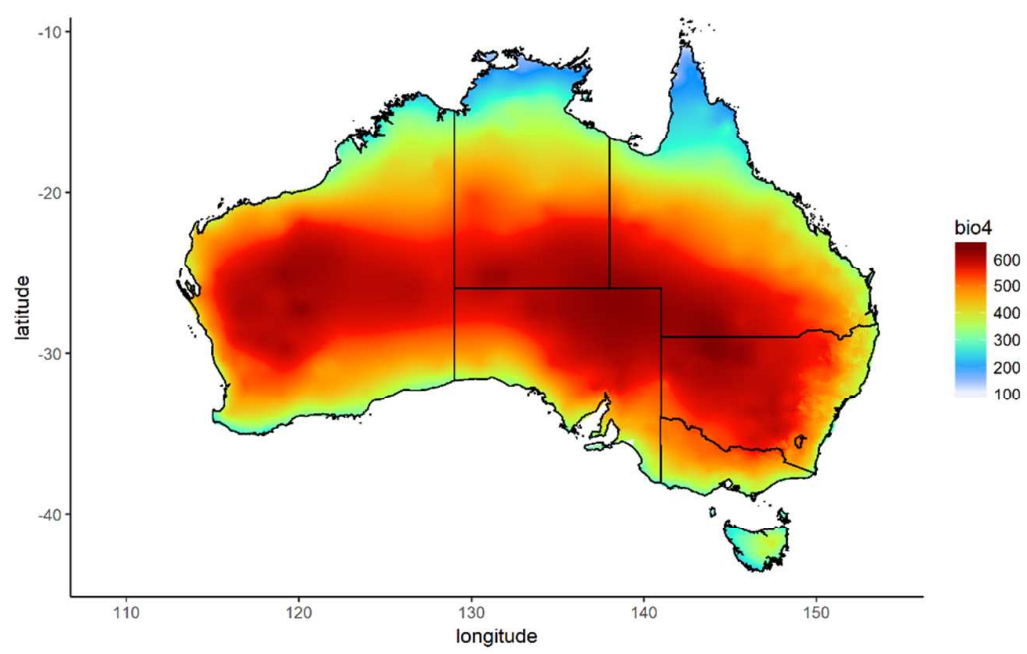

Figure S3, Bio4: Temperature seasonality expressed as the standard deviation of the weekly monthly mean temperatures divided by mean of those temperatures in degrees Kelvin.
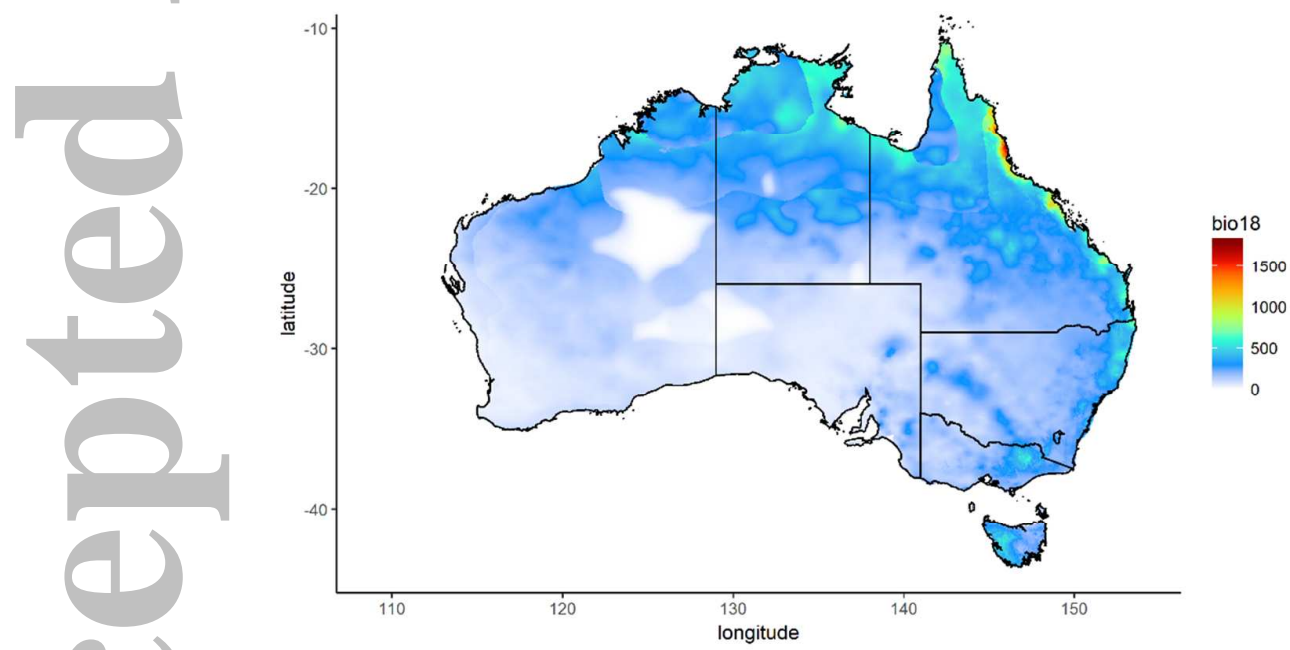

Figure S4. Bio18: Mean precipitation of warmest quarter determined to the nearest month in $\mathrm{mm}$ of rain.

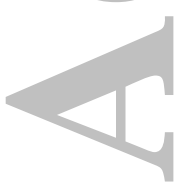




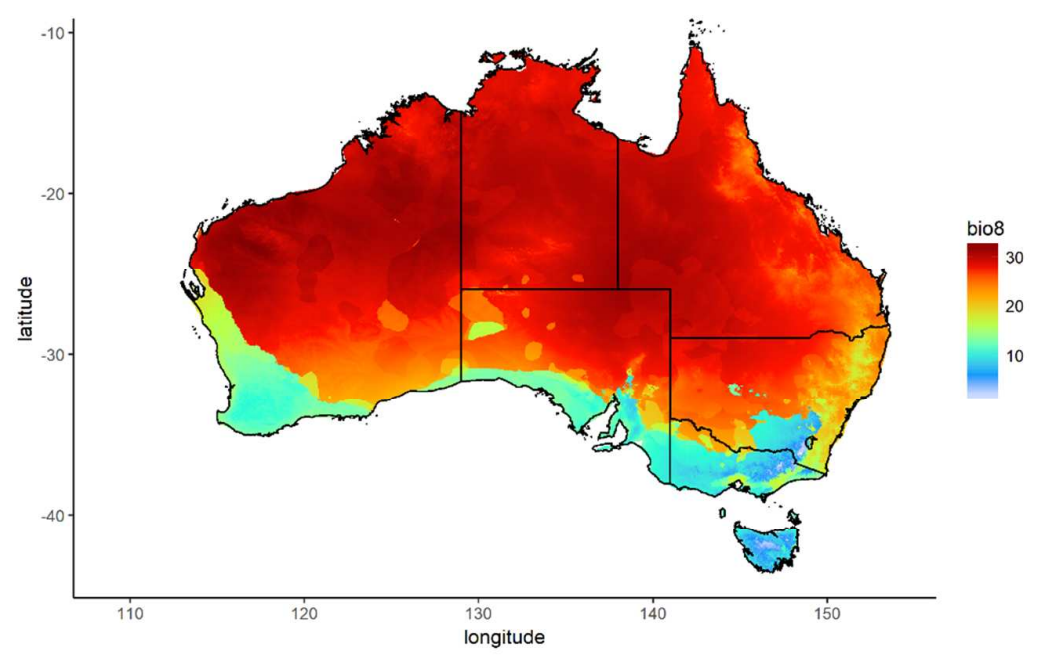

Figure S5. Bio8: Mean temperature of wettest quarter determined to the nearest month in degrees Celsius.

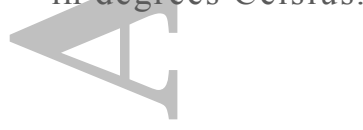

Aridity layer

As with the BIOCLIM layers, available precomputed aridity layers are constructed using monthly averaged climatic data (years spanning 1950-2000). To make the temporal dimensions of input data congruent, we recomputed the aridity layer using summary daily gridded climatic data from the Australian Bureau of Meteorology spanning 1996-2015 (0.05-degree resolution) converted into monthly averages following Hargreaves et al. (1985) and Zomer et al. (2008) where Aridity Index = MAE/MAP (MAP is the mean annual precipitation ( $\mathrm{mm} / \mathrm{y}$ ) and MAE is the mean annual evapotranspiration $(\mathrm{mm} / \mathrm{y}))$. Fig. S6 depicts the computed aridity layer used in the analysis presented in the main text.

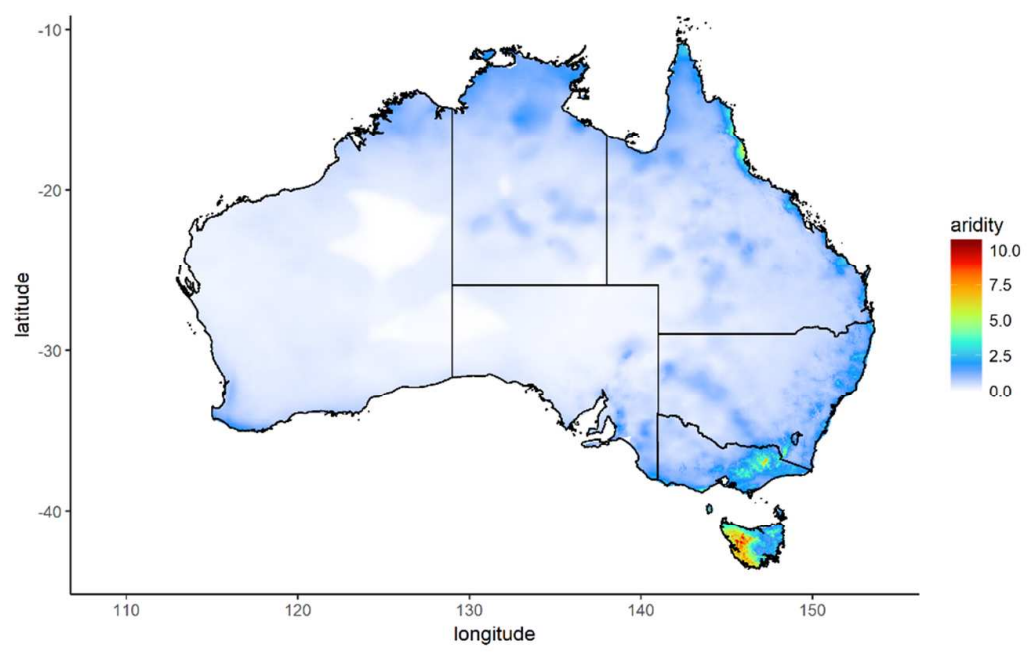


Figure S6. Aridity index or the ratio of mean annual evapotranspiration $(\mathrm{mm} / \mathrm{y})$ to precipitation $(\mathrm{mm} / \mathrm{y})$

\section{Voltinism layer}

To estimate voltinism (number of generations per year) we required general methods to first calculate 1) the cessation of diapause in autumn, 2) the commencement of diapause in spring, and 3) the temperature response of lifecycle duration so that the number of generations can be predicted between these two timepoints. Gridded data on daily climatic conditions was derived from 20-year averages of gridded climatic data spanning 1996-2015 (0.05-degree resolution) from the Australian Bureau of Meteorology.

The cessation of diapause was estimated using a model developed in 2005, which predicts the week of 90\% diapause from daylength and long-term growing season (Ridsdill-Smith et al., 2005). The formula for diapause is expressed in terms of $\mathrm{Y}$ (weeks from diapause, where $90 \%$ diapause occurs at $\mathrm{Y}=0$ ), long-term growing-season (defined as the number of months for which rainfall $(\mathrm{mm})>2 \mathrm{x}$ temperature $\left.\left({ }^{\circ} \mathrm{C}\right)\right)$, and daylength $(\mathrm{h})$ :

$$
\mathrm{Y}=-44.487+0.06487 \times(\text { daylength })-1.1163 \times(\text { long-term growing season })
$$

This equation is solved for $\mathrm{Y}=0$, i.e. week of $90 \%$ diapause, the timing of which is resolved from daylength for a particular location (e.g. we used the R function daylength in the geosphere package).

The cessation of diapause was estimated using a recently developed model for predicting the timing of RLEM egg hatches across Australia from a combination of cumulative rainfall and cold temperatures (McDonald et al., 2015). Different functions were found to best fit WA and the southeastern part of their distribution. For WA, egg hatch was triggered for the first day in the year that was preceded by 5 $\mathrm{mm}$ of rainfall in the previous 5 days and an average MDT of less than $20.5^{\circ} \mathrm{C}$ for the previous 10 days $\left(M D T=T_{\max }-\left(T_{\max }-T_{\min }\right) / 4\right.$ where $T_{\max }$ and $T_{\min }$ is daily maximum and minimum temperatures in ${ }^{\circ} \mathrm{C}$ respectively). Hatching was triggered in the same way for southeastern Australia with the exception that the temperature threshold for development was lower at $16^{\circ} \mathrm{C}$. An additional day was added to the hatch date to account for the deutovum stage, and a development penalty for 0.83 days

for each $0.1^{\circ} \mathrm{C}$ the mean temperature was over $19^{\circ} \mathrm{C}$.

Finally, lifecycle duration was estimated to require 5 weeks to complete at a temperature cycle of $10 \mathrm{~h}$ at $18^{\circ} \mathrm{C}, 14 \mathrm{~h}$ at $11^{\circ} \mathrm{C}$ (Ridsdill-Smith \& Gaull, 1995), which was adjusted for a temperature using Boltzmann-Arrhenius equation with inhibition at temperatures under $4^{\circ} \mathrm{C}$ and over $30^{\circ} \mathrm{C}$ based on developmental rate data (James \& O'Malley, 1991). Temperature correction factor for temperature $(\mathrm{T})$ in Kelvin with reference temperature $\left(\mathrm{T}_{\text {ref }}\right)$ was defined as: 


$$
K(T)=\exp \left(\frac{T_{A}}{T_{r e f}}-\frac{T_{A}}{T}\right) \cdot \frac{1+\exp \left(\frac{T_{A L}}{T_{r e f}}-\frac{T_{A L}}{T_{L}}\right)+\exp \left(\frac{T_{A H}}{T_{H}}-\frac{T_{A H}}{T_{r e f}}\right)}{1+\exp \left(\frac{T_{A L}}{T}-\frac{T_{A L}}{T_{L}}\right)+\exp \left(\frac{T_{A H}}{T_{H}}-\frac{T_{A H}}{T}\right)}
$$

where $\mathrm{T}_{\mathrm{A}}$ (Arhennius temperature, ${ }^{\circ} \mathrm{K}$ ) $=8000, \mathrm{~T}_{\mathrm{H}}=273+30, \mathrm{~T}_{\mathrm{L}}=273+5, \mathrm{~T}_{\mathrm{AH}}=135000$, and $\mathrm{T}_{\mathrm{AL}}$ $=20110$. The temperature response of generation time is depicted graphically in Fig. S7.
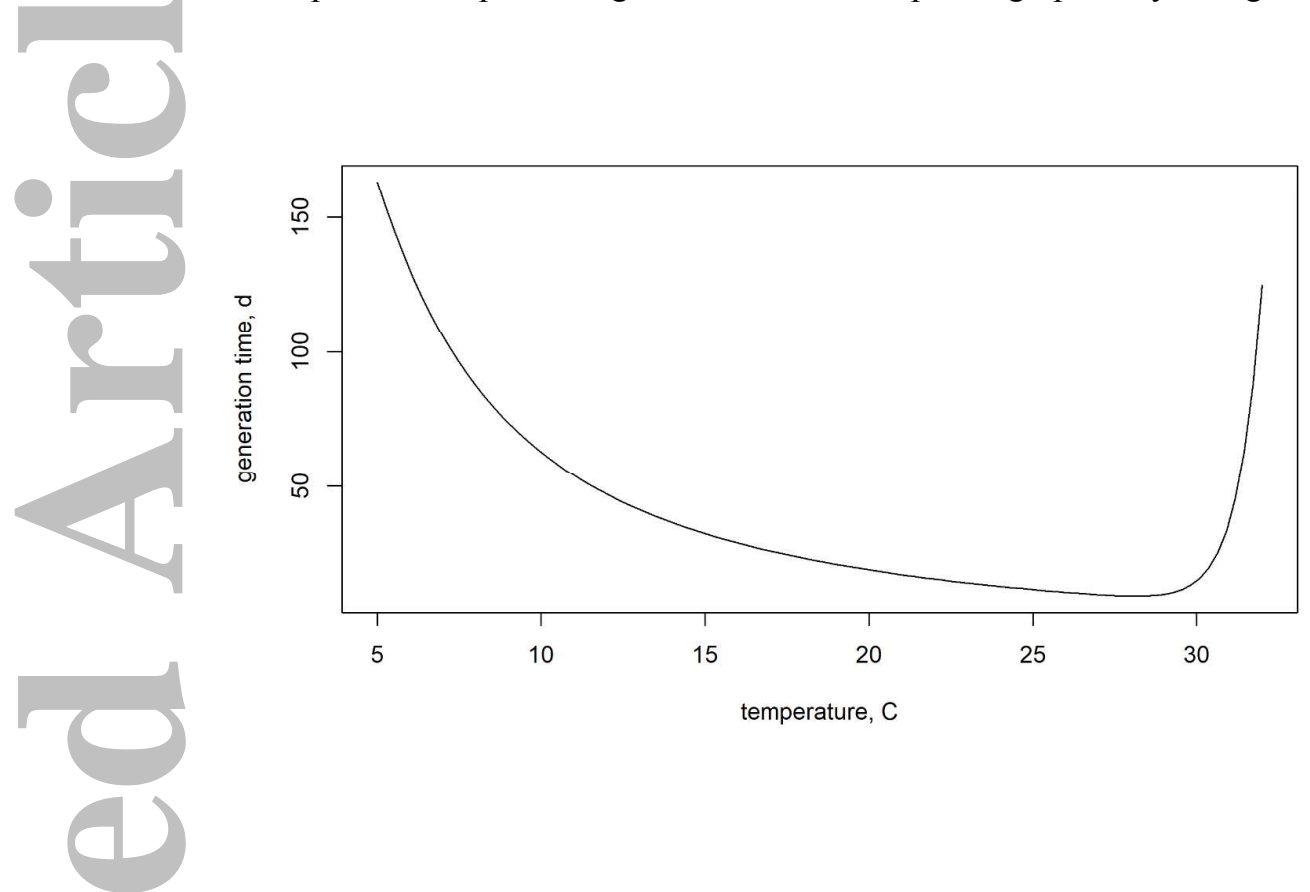

temperature, $\mathrm{C}$

Figure S7. Estimated temperature response of generation time for the redlegged earth mite.

Together, this information was used to construct an estimate of the number of possible generations (assuming survival) as depicted in Fig. S8.

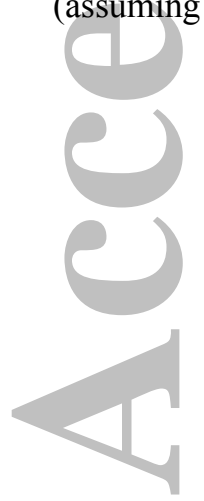



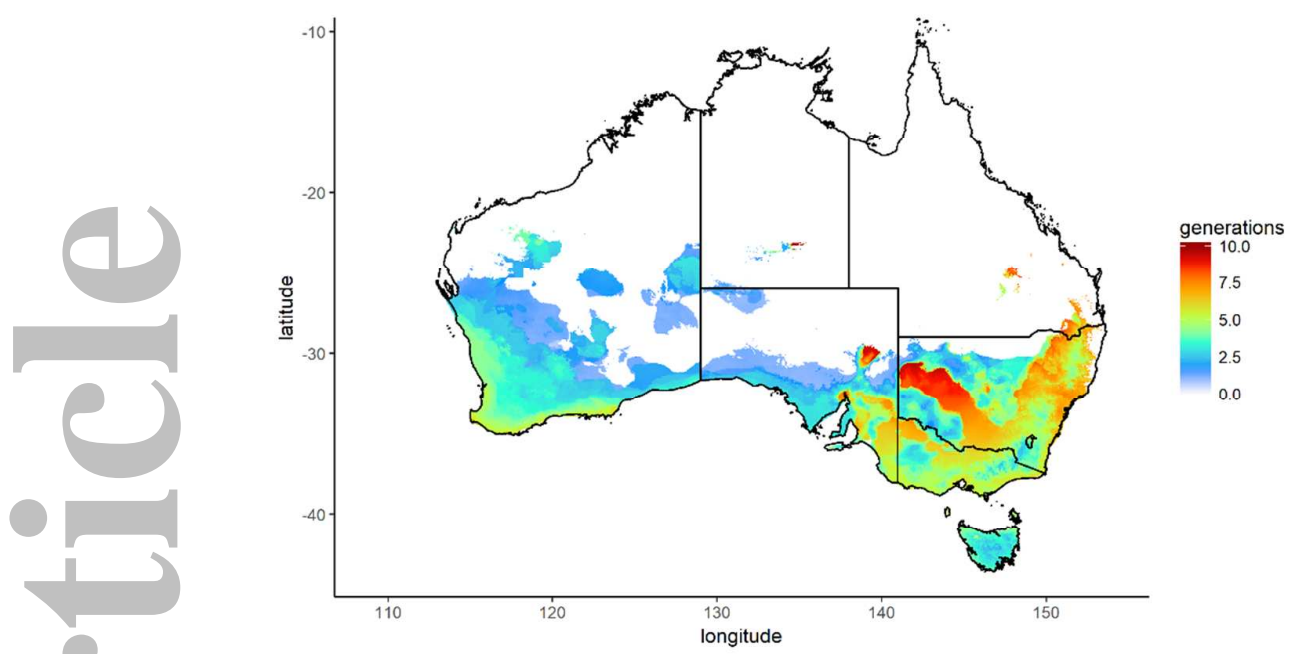

Figure S8. Voltinism as measured as generations per year.

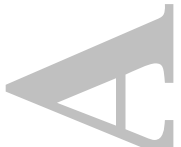

Land usage layer

Land usage was a categorical variable estimated from the same land usage data used in constructing

the pyrethroid usage layer. As the land usage layer was at a higher resolution (0.01-degree) than that at which the analysis was conducted (0.05), we aggregated the land usage by choosing the most common category reported for each 0.05 -degree grid cell. Instead of aggregating across the two years, we include two categorical variables for each of the 2005-6 and 2010-11 periods (see Fig. S9).

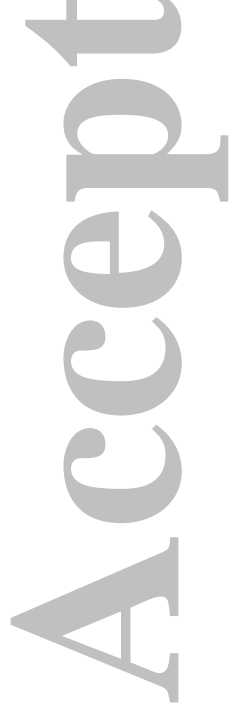



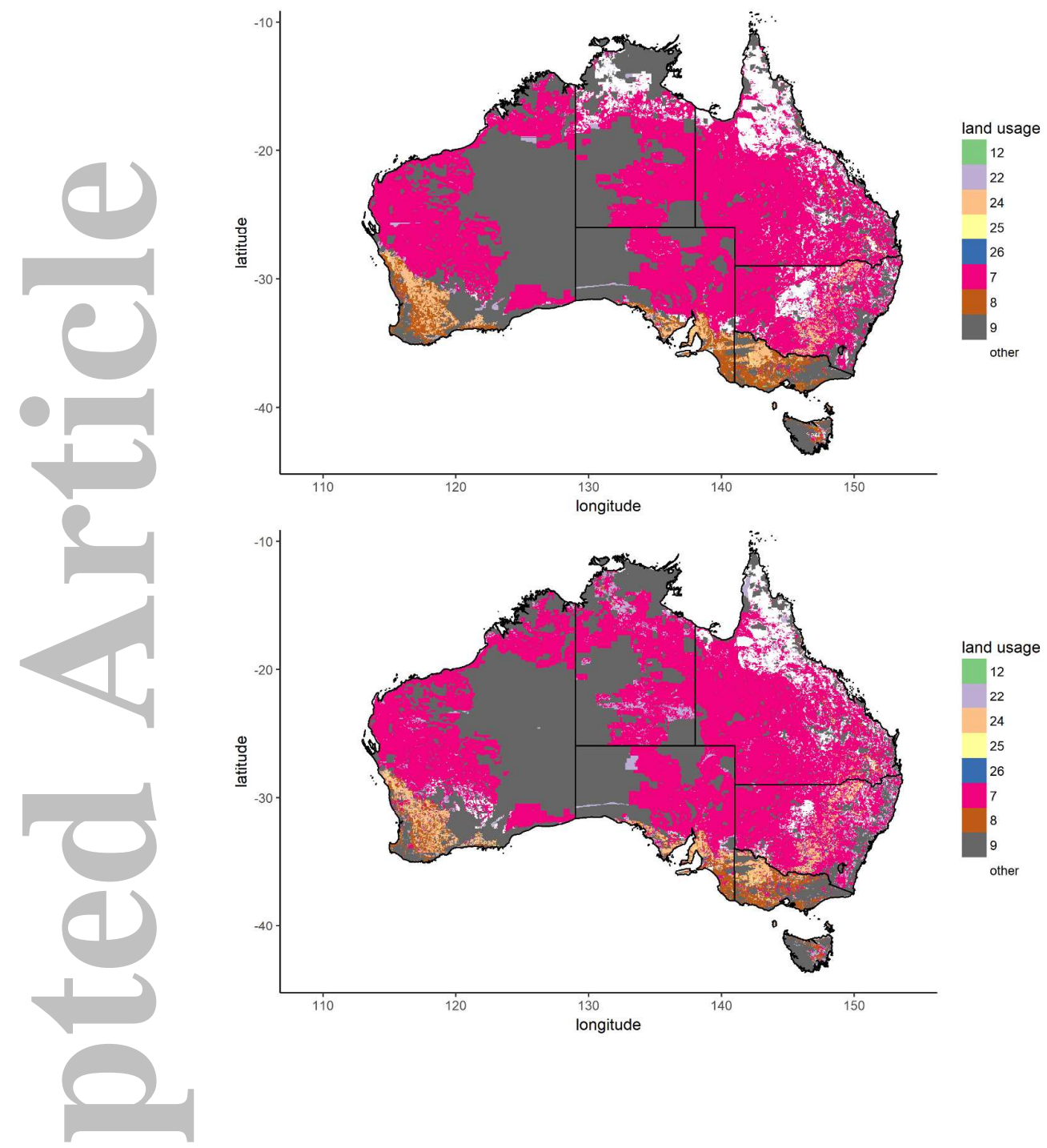

Figure S9. Land usage category as reported. Land usage data provided by the Australian Collaborative Land Use and Management Program (ACLUMP) for 2005-6 (top) and 2010-11 (bottom). We show only those categories used in the analysis, i.e. the 413 locations used in the analysis only belonged to 8 unique land usage categories of the 26 available. The key is defined as follows: 7: Grazing - native or naturalised pasture or native-exotic pasture mosaic, 8: Grazing sown pastures, 9: Non-agricultural land or no data, 12: Pastures and crops for hay or pasture seed, 22: Unallocated agricultural land, 24: Winter cereals, 25: Winter legumes, 26: Winter oilseeds.

Land usage in 2005-6 and 2010-11 was ranked as the two least important predictor variables, and so was excluded from the analysis along with the bio8 variable. From the fitted responses of land usage below (before exclusion), a few points can be made. There were opposing responses of the categories across the two periods, likely indicating spurious correlations (e.g. category 8: Grazing sown pastures 
was positively associated in the first period but negatively associated in the next). However, category 9: Non-agricultural land or no data and was positively associated across both periods, while 7:

Grazing - native or naturalised pasture or native-exotic pasture mosaic was negatively associated across both periods. This would seem to make sense with the zero pesticide usage estimated for the former likely to be an underestimate, and pesticide usage in the latter likely to be exceptionally low.

Although these land usage variables did not improve the overall model substantially, they may indicate possible limitations in our estimate of pyrethroid usage.

Correlation of predictor variables

None of the variables included in the model were highly correlated (taken as $>0.8$ correlation coefficient), however, regression trees are robust to any multicollinearity as irrelevant variables are simply ignored in the fitting procedure, i.e. are not used as criteria for branching (Friedman, 2002). Fig. S10 shows the bivariate correlation structure of predictor variables and was constructed with the chart.Correlation() function from the PerformanceAnalytics R package (Peterson et al., 2015).

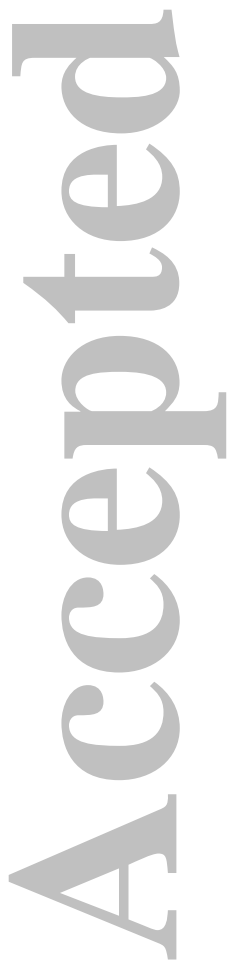




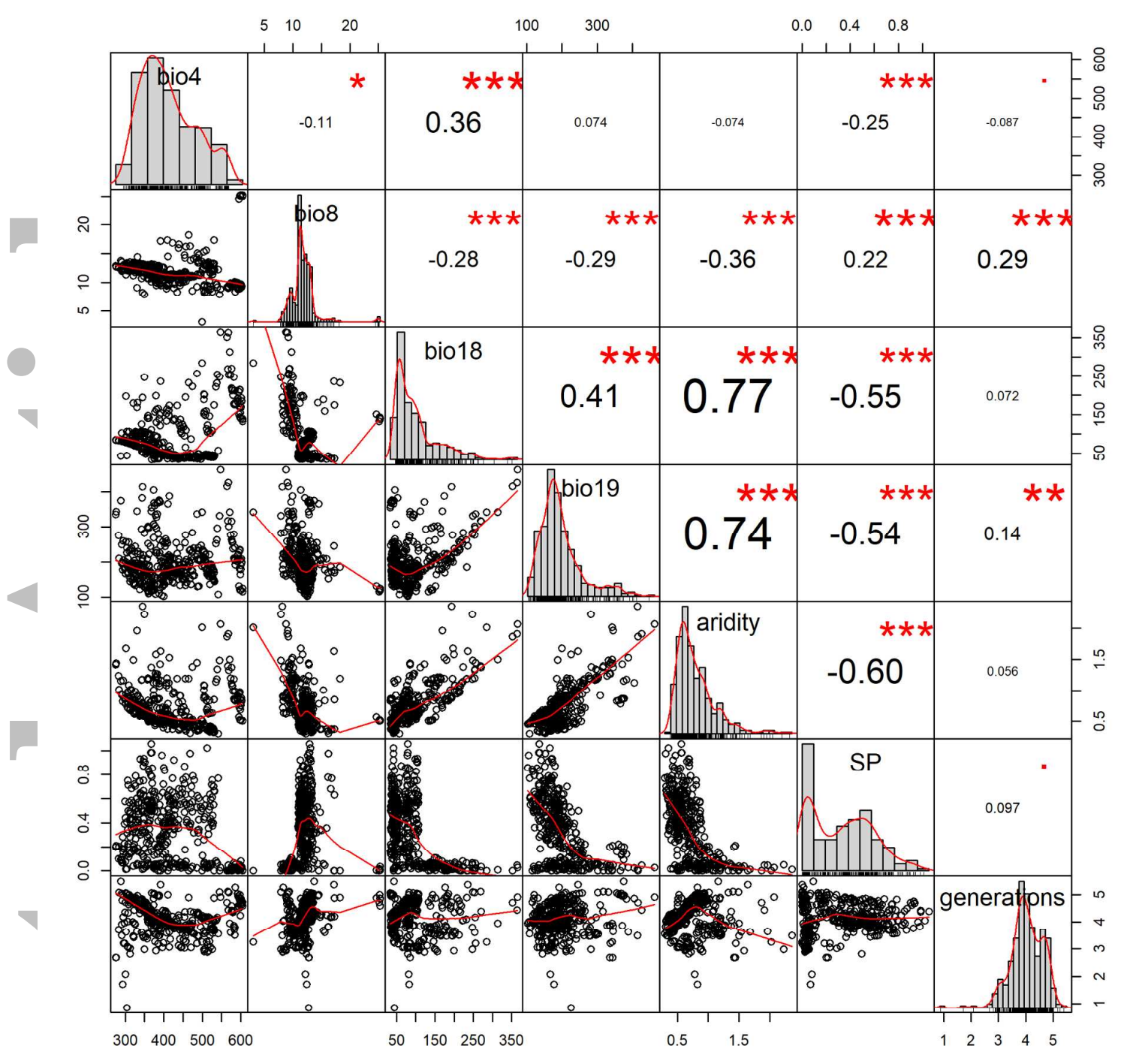

Figure S10. A correlation plot of numerical model predictors. The top triangle of the matrix includes Pearson's product moment correlation coefficients and significance (* $\mathrm{p}<0.05, * * \mathrm{P}<0.01, * * \mathrm{P}<0.001)$. In the lower triangle of the matrix, bivariate scatterplots are shown, with a fitted line. The leading diagonal indicates the distribution of data points for each variable. The predictor names correspond as follows: Seasonality (bio_4); Rainy season temperature (bio_8*); Summer precipitation (bio_18); Winter precipitation (bio_19); Selection (SP); Aridity; Generations.

Interactions

Pairwise interaction strength can be examined through projecting model predictions to a grid of values for each pair of predictors (with all other predictors held at their mean level). These model predictions 
can then be linearly regressed against the two predictors (modelled categorically instead of numerically and without interaction). This method essentially identifies deviations of the BRT model predictions from linear combinations of each predictor pair, which indicate interactions. Scaling these interactions to relative scale, such that the sum of all relative interactions is 100 (Table S2), shows the relative interaction strength. While there is no threshold value that constitutes a significant interaction, Table S2 shows the relative importance of the interaction strength shows moderate variability, but the plot of the strongest interaction (Fig. S11) does not indicate a major effect in absolute terms.

Table S2 - Relative pairwise interaction strength of final model numerical predictor variables

\begin{tabular}{|c|c|c|c|c|c|}
\hline & $\begin{array}{l}\text { Summer } \\
\text { precipitation }\end{array}$ & $\begin{array}{l}\text { Winter } \\
\text { precipitation }\end{array}$ & Aridity & Selection & Generations \\
\hline Seasonality & 8.34 & 0.49 & 5.1 & 12.95 & 2.82 \\
\hline Summer precipitation & & 2.19 & 7.13 & 2.09 & 12.36 \\
\hline Winter precipitation & & & 0.92 & 1.72 & 0.33 \\
\hline Aridity & & & & 1.57 & 0.43 \\
\hline Selection & & & & & 0.79 \\
\hline
\end{tabular}
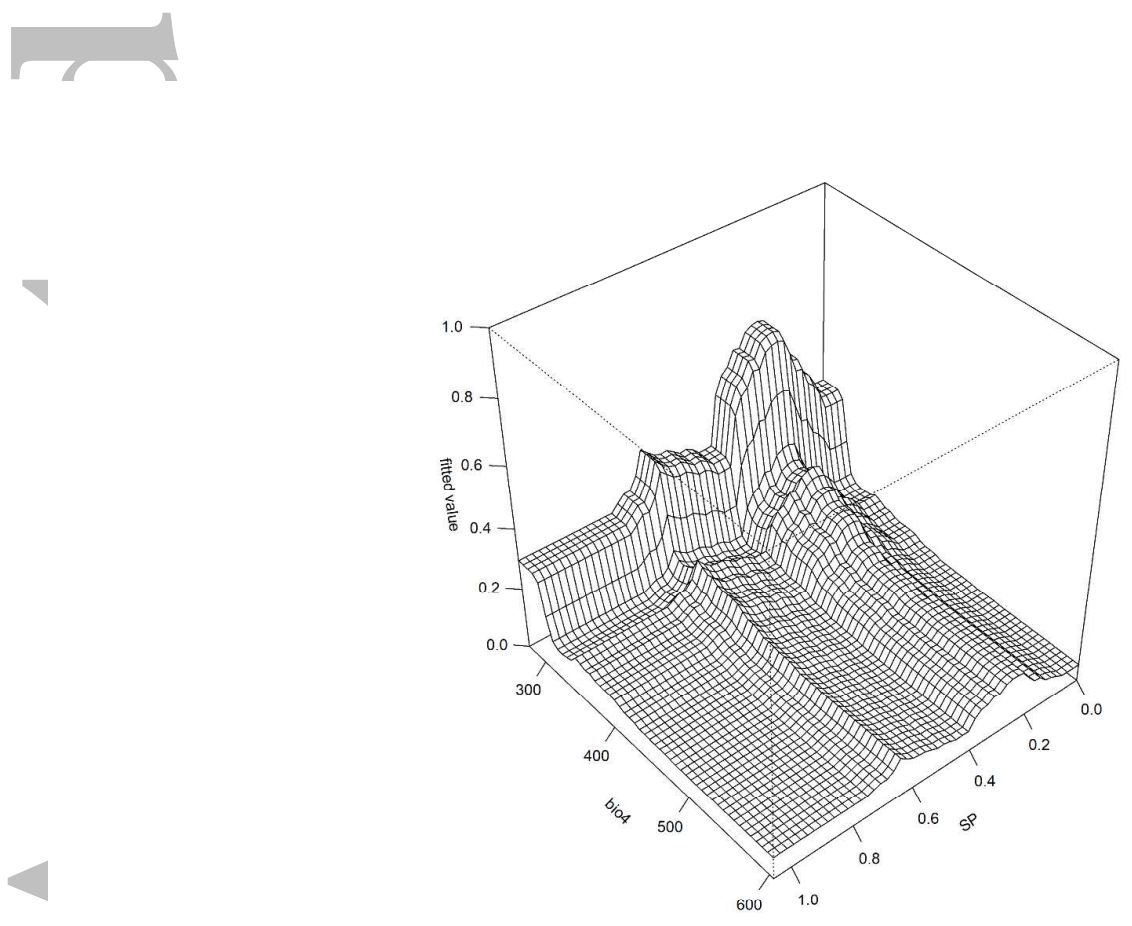

Figure S11. Three-dimensional partial dependence plots for the strongest interaction (pyrethroid usage (SP) and temperature seasonality (bio4)) in the model for pyrethroid resistance. In generating this grid of predicted values, all variables except those graphed are held at their means. 


\section{Mechanism of pyrethroid resistance}

A recent study on pyrethroid resistance in redlegged earth mites (by Owain R Edwards, Thomas K Walsh, Suzanne Metcalfe, Wee Tek Tay, Ary Hoffmann, Peter Mangano, Alan Lord, Svetlana Micic, and Paul Umina) found a tight association between two synonymous mutations at a locus coding for a voltage-gated sodium channel gene and survival in the pyrethroid resistance bioassay. The same mutations are known to confer knockdown resistance $(k d r)$ to pyrethroids in a range of species (Roush and Tabashnik 1990). Mite populations sampled across Western Australian as part of resistance surveillance were passed through a discriminating dose of $0.1 \mathrm{~g} / \mathrm{L}$ of bifenthrin and scored as dead or alive. These populations exhibited a strong association with the presence of $k d r$ and survival (see graph below). The linear relationship is suggestive of intermediate dominance, and indicates population variation in resistance.

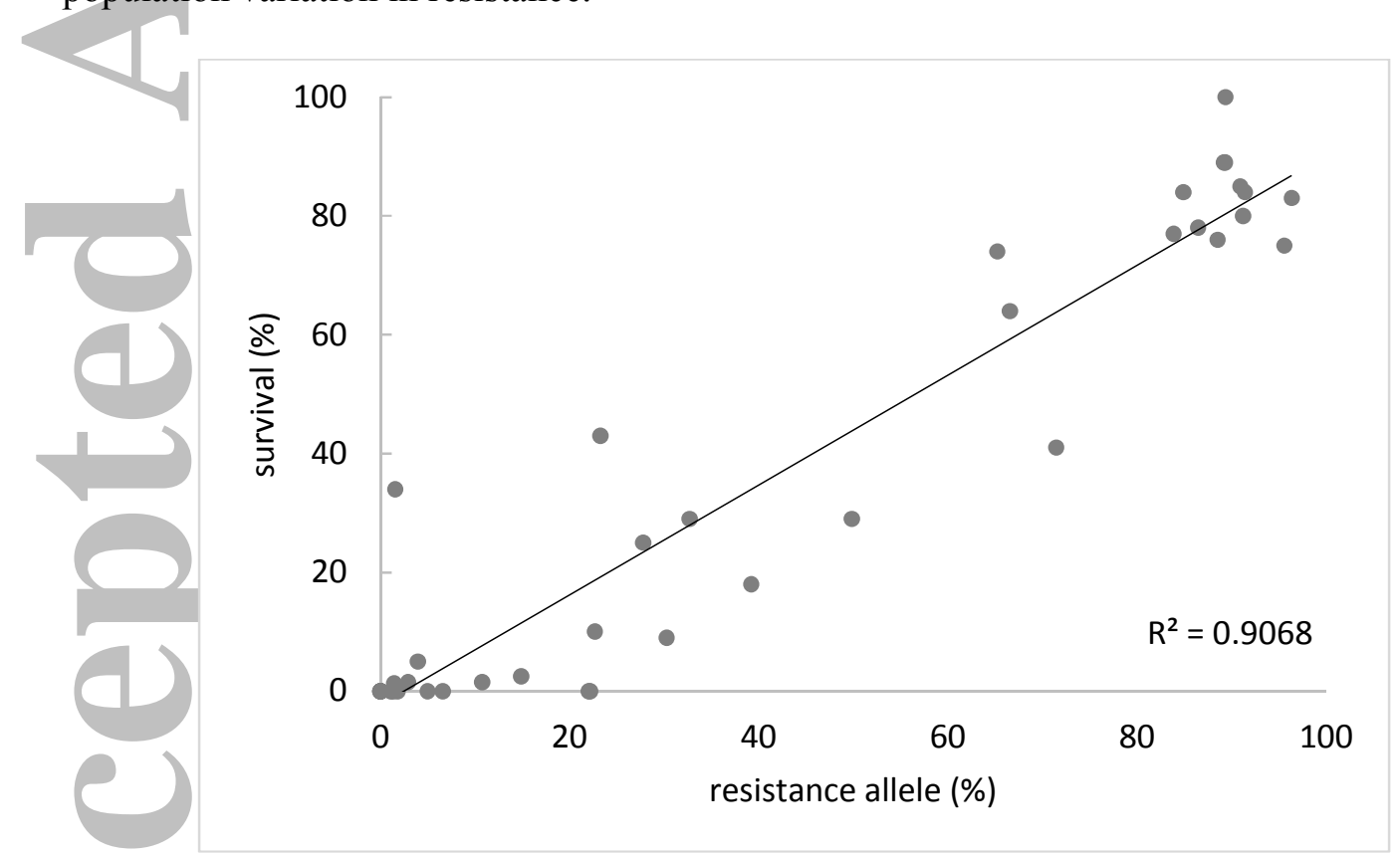

Figure S12. Regression plot of percent survival of mites after $24 \mathrm{hr}$ exposure to a diagnostic dose of bifenthrin versus percent resistance allele from field populations collected in 2014. Figure adapted from a paper currently under revision (O. R. Edwards et al. 2017). 


\section{References}

In revision

Edwards, O.R., Walsh, T.K., Metcalfe, S., Tay, W.T., Hoffmann, A.A., Mangano, P., Lord, A., Micic, S. \& Umina, P.A. (2017) A genomic approach to understanding pyrethroid resistance in the redlegged earth mite, Halotydeus destructor, (In revision)

\section{Published}

Friedman, J.H. (2002) Stochastic gradient boosting. Computational Statistics and Data Analysis, 38, 367-378.

Hargreaves, G.L., Hargreaves, G.H. \& Riley, J.P. (1985) Irrigation Water Requirements for Senegal River Basin. Journal of Irrigation and Drainage Engineering, 111, 265-275.

James, D.G. \& O'Malley, K.J. (1991) Effect of temperature on development and survival of eggs of Halotydeus destructor (Tucker) (Acari: Penthaleidae). International Journal of Acarology, 17, 37-41.

McDonald, G., Umina, P.A., Macfadyen, S., Mangano, P. \& Hoffmann, A.A. (2015)

Predicting the timing of first generation egg hatch for the pest redlegged earth mite Halotydeus destructor (Acari: Penthaleidae). Experimental and Applied Acarology, 65, 259-276.

Peterson, B., Carl, P., Boudt, K., Bennett, R., Ulrich, J., Zivot, E., Lestel, M., Balkissoon, K. \& Wuertz, D. (2015) Package “PerformanceAnalytics.” R package version.

Ridsdill-Smith, T.J. \& Gaull, K.R. (1995) An improved method for rearing Halotydeus destructor (Acari: Penthaleidae) in the laboratory. Experimental and Applied Acarology, 19, 337-345.

Ridsdill-Smith, T.J., Pavri, C., De Boer, E. \& Kriticos, D. (2005) Predictions of summer diapause in the redlegged earth mite, Halotydeus destructor (Acari: Penthaleidae), in Australia. Journal of Insect Physiology, 51, 717-726.

Roush, R.T. \& Tabashnik, B.E. (1990) Pesticide resistance in arthropods, Springer Science \& Business Media, Berlin.

Zomer, R.J., Trabucco, A., Bossio, D.A. \& Verchot, L. V. (2008) Climate change mitigation: 
A spatial analysis of global land suitability for clean development mechanism afforestation and reforestation. Agriculture, Ecosystems and Environment, 126, 67-80.
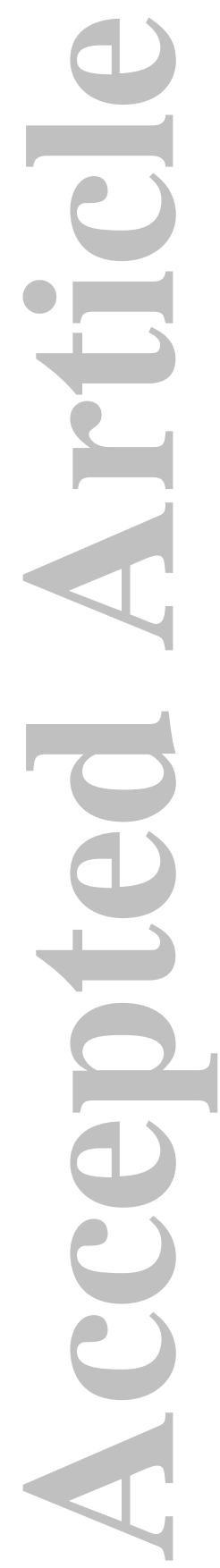


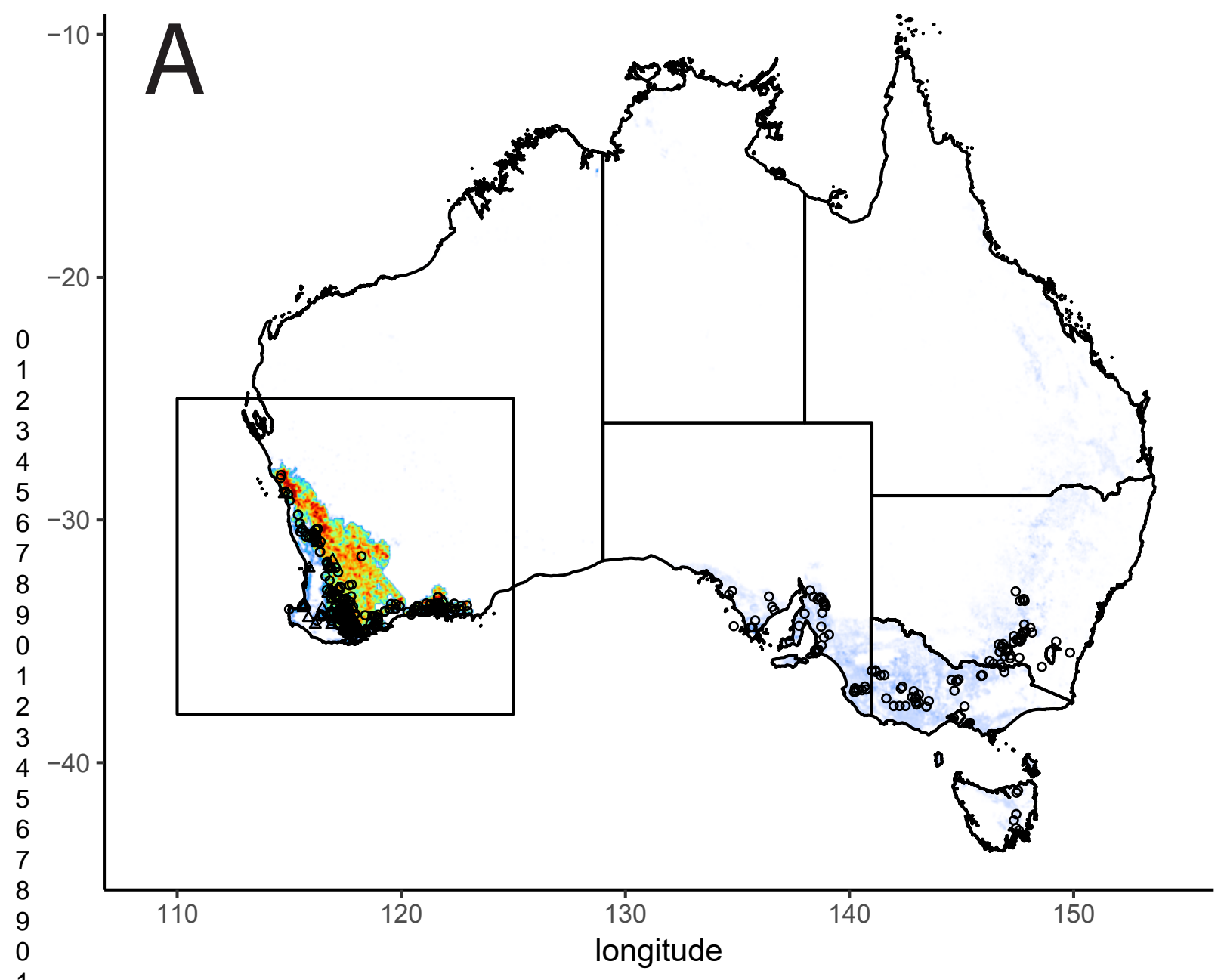

B

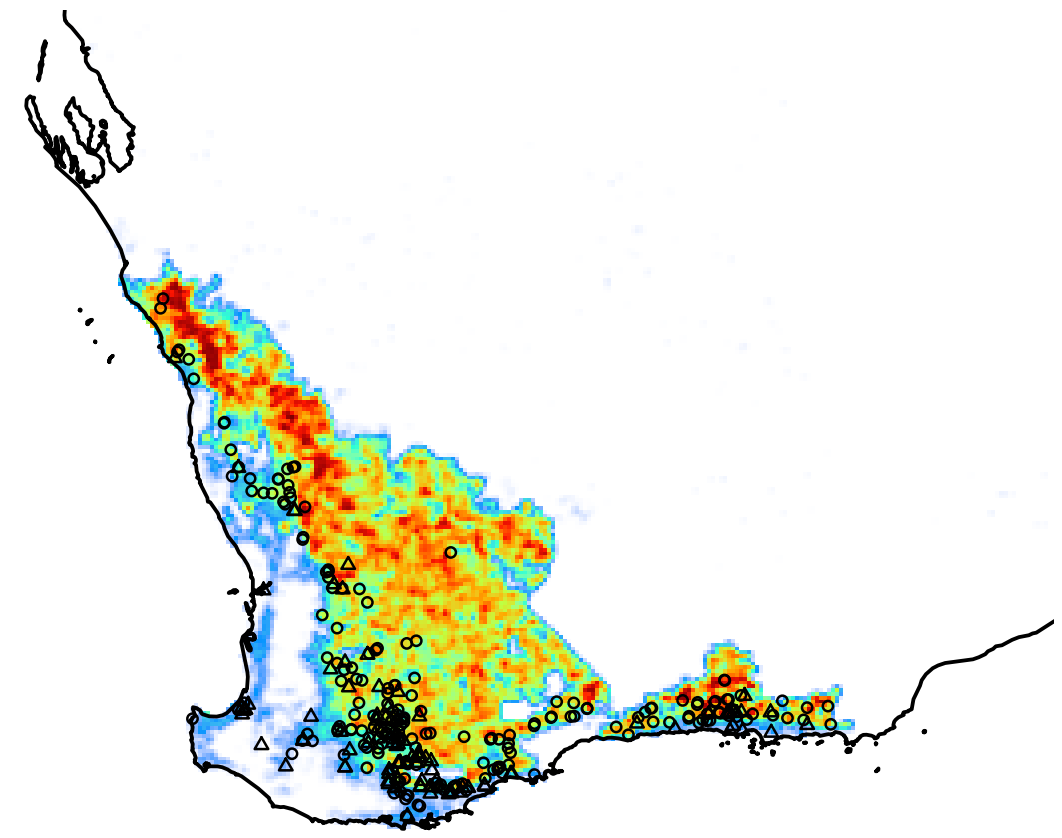

yearly sprays

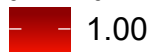

0.75

0.50

0.25

longitude

This article is protected by copyright. All rights reserved. 


\section{Page 47 of 48}

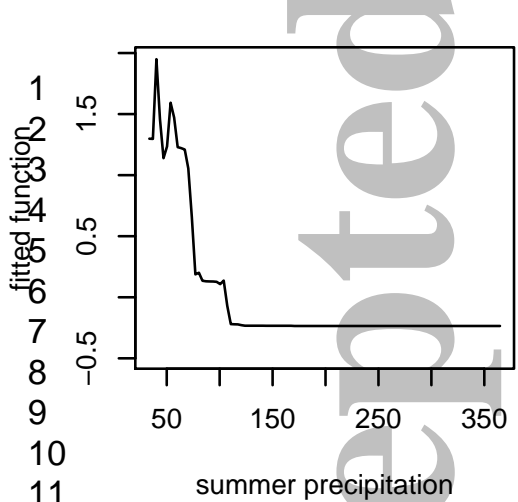

11

12

13

14

15

16

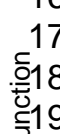

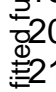
22 23 24 25 26 27

\section{Global Ecology and Biogeography}
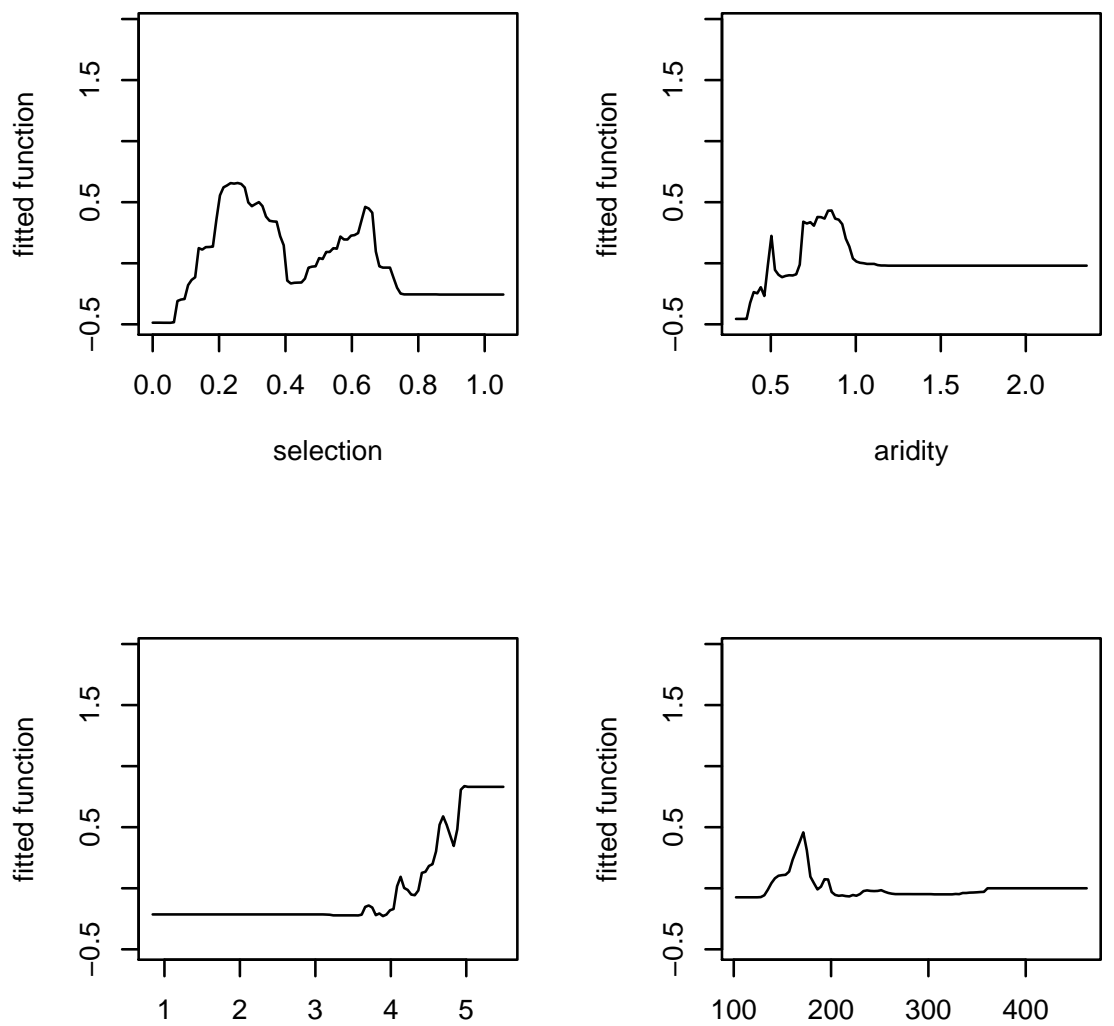

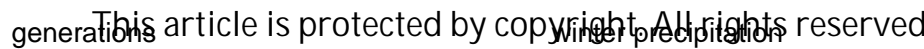



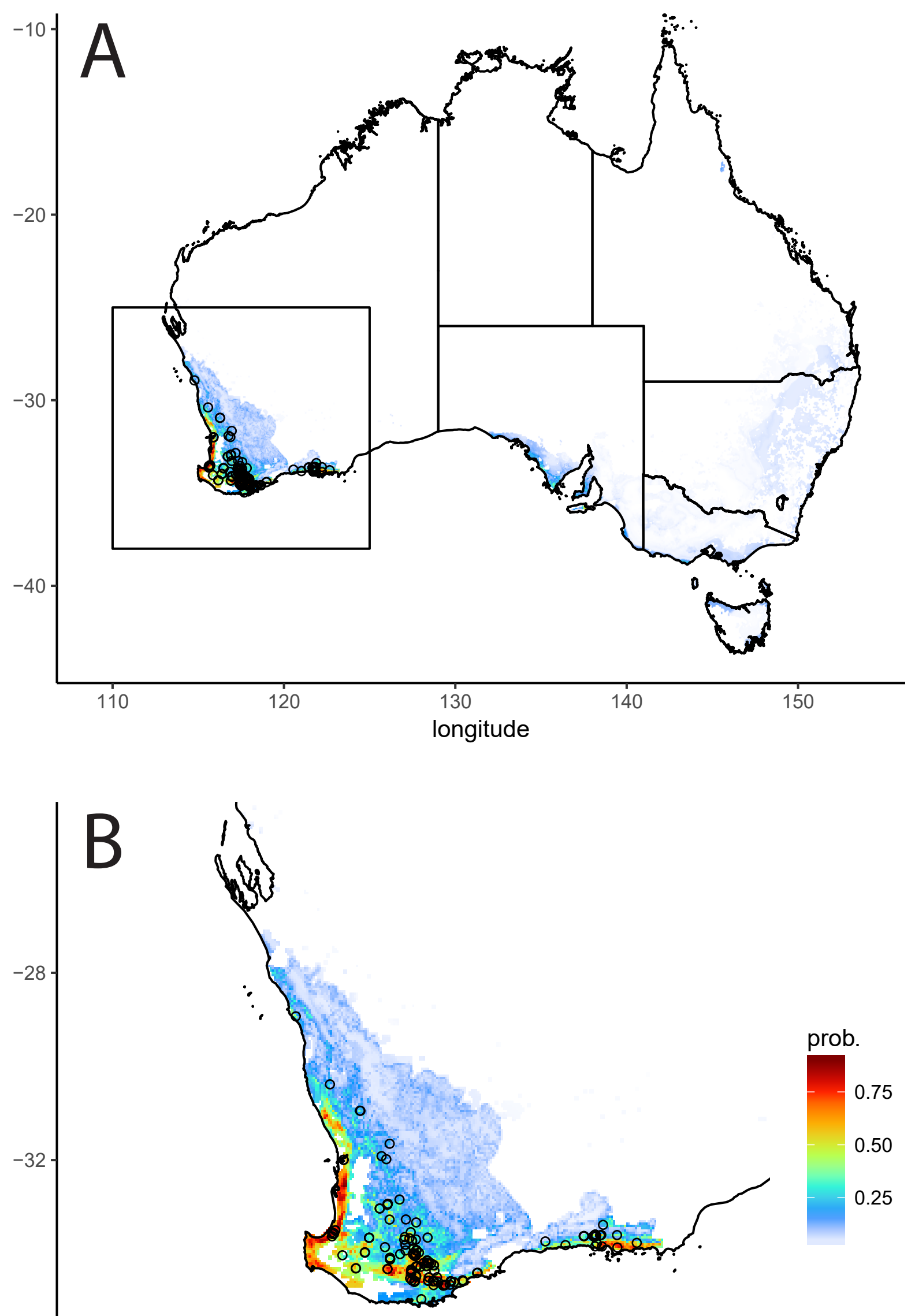


\section{University Library}

\section{- M M I N E R VA A gateway to Melbourne's research publications}

Minerva Access is the Institutional Repository of The University of Melbourne

Author/s:

Maino, JL;Umina, PA;Hoffmann, AA

Title:

Climate contributes to the evolution of pesticide resistance

Date:

2018-02-01

Citation:

Maino, J. L., Umina, P. A. \& Hoffmann, A. A. (2018). Climate contributes to the evolution of pesticide resistance. GLOBAL ECOLOGY AND BIOGEOGRAPHY, 27 (2), pp.223-232. https://doi.org/10.1111/geb.12692.

Persistent Link:

http://hdl.handle.net/11343/293989 